\title{
Influences of Continental Monsoons and Air-Sea Coupling on the Climate of the Equatorial Pacific*
}

\author{
Xiouhua Fu AND Bin WANG \\ International Pacific Research Center, and Department of Meteorology, School of Ocean and Earth Science and Technology, \\ University of Hawaii at Manoa, Honolulu, Hawaii
}

(Manuscript received 30 April 2002, in final form 23 December 2002)

\section{ABSTRACT}

\begin{abstract}
An air-sea-land coupled model of intermediate complexity was used to reveal the important roles of air-sea coupling and adjacent continental monsoons (i.e., American monsoons and Asian-Australian monsoons) on the annual cycle and mean state of the equatorial Pacific.

Excluding the effects of adjacent continental monsoons, the simulated mean SST in the western Pacific displays a warm bias; the SST seasonal cycle exhibits an erroneous, dominant annual component in the western Pacific, and insufficient strength and a 2-month phase delay in the equatorial eastern Pacific. The air-sea coupling alone cannot sustain the full strength of the annual marches of the ITCZ/cold tongue complex. This is because the diabatic heating associated with the ITCZ rainfall generates both a southerly and a westerly component to its equatorward side; while the southerly cools the cold tongue establishing a positive feedback to enhance the ITCZ, and the equatorial westerly favors cold tongue warming inducing a negative feedback that offsets the effect of the southerly component.

Including the influences from the adjacent continental monsoons significantly improves the simulations of the mean state and annual cycle of the equatorial Pacific. The Asian-Australian monsoons are found to improve the mean SST through enhancing the strength of the trades and to yield a correct semiannual cycle of surface wind speed and SST in the equatorial western Pacific. However, they have little influence on the annual cycle in the eastern Pacific SST. In contrast, the South American monsoon exerts profound impacts on the annual variations of the southeast trades and SST in the eastern Pacific, but not the mean SST. The Colombian and North American continental monsoons have little impact on the annual cycle of SST in the cold tongue.
\end{abstract}

\section{Introduction}

Both the mean state and annual cycle of the equatorial Pacific have significant influences on the low-frequency climate variability in the tropical Pacific. Zebiak and Cane (1987) indicated that the mean state determines the spatial structure of the El Niño-Southern Oscillation (ENSO) and the annual cycle impacts the air-sea coupling strength. Jin et al. (1994) further pointed to the annual cycle as a fundamental pacemaker of ENSO. Wang and An (2002) found that a number of ENSO properties (e.g., period, amplitude, structure, and propagation) are very sensitive to the basic state of the equatorial Pacific. The successful simulation of tropical intraseasonal oscillation is also strongly dependent on the

\footnotetext{
* School of Ocean and Earth Science and Technology Publication Number 6152 and International Pacific Research Center Publication Number 208.
}

Corresponding author address: Dr. Xiouhua Fu, IPRC, SOEST, University of Hawaii at Manoa, 1680 East-West Road, Post Bldg. 4th Floor, Honolulu, HI 96822.

E-mail: xfu@ soest.hawaii.edu mean surface winds in the western equatorial Pacific (Inness et al. 2003). On the other hand, our understanding of and ability to realistically simulate the mean state and annual cycle of the equatorial Pacific are very limited (Mechoso et al. 1995; Schneider 2002). The main objective of this study is trying to extend our understanding of the mean state and annual cycle of the equatorial Pacific with an air-sea-land coupled model, based on the previous studies with the Pacific-only air-sea coupled models (Chang and Philander 1994; Xie 1994, 1998; Liu and Xie 1994; Neelin and Dijkstra 1995; Chang 1996; Li and Philander 1996; Jin 1998; Wang and Wang 1999; among others).

The most intriguing issues associated with the mean state and annual cycle of the equatorial Pacific are the formation and evolution of Walker circulation and the intertropical convergence zone (ITCZ)/cold tongue complex (Philander 1990; Mitchell and Wallace 1992; Wang 1994). Air-sea coupling in the tropical Pacific Ocean plus the tilted coastline of the American continent are viewed as the essential factors to solve these puzzles (Neelin and Dijkstra 1995; Philander et al. 1996; Jin 1998; Xie 1998; Wang and Wang 1999; Xie and Saito 2001). Neelin and Dijkstra (1995) and Jin (1998) intro- 
duced a concept of the "climatological version of the Bjerknes hypothesis" to explain the Walker circulation and the equatorial warm pool/cold tongue structure. Xie (1998) further emphasized the importance of southerly cross-equatorial winds on maintaining the cold tongue in the eastern Pacific. Philander et al. (1996) attributed the formation of the ITCZ/cold tongue complex to the tilted coastline of the American continent and the positive feedback between the low-level stratus and sea surface temperature (SST) in the southeast Pacific. This idea has been further elaborated by Xie and Saito (2001). With a two-dimensional intermediate model, Wang and Wang (1999) suggested that the interaction between the ITCZ and the cold tongue in the eastern Pacific is able to provide a self-maintenance mechanism for the ITCZ to linger in one hemisphere.

The important role of air-sea coupling on the annual cycle has been proposed by Horel (1982) through the observation of the coherent westward propagation of SST and zonal wind along the equatorial Pacific. Mitchell and Wallace (1992) further suggested that the annual marches of the ITCZ and the cold tongue in the eastern Pacific are strongly coupled with each other. Triggered by the onset of summer monsoon convection over Colombia and Central America in early summer, the nearby ITCZ convection strengthens northward surface winds, which reestablish the equatorial cold tongue through driving the near-equatorial upwelling (Chang and Philander 1994). The cooling near the equator raises local sea level pressure and increases northward pressure gradient and surface winds, thus further enhancing the convection in the ITCZ. A positive feedback is established to maintain this ITCZ/cold tongue complex. Xie (1994), with a simple coupled model, found that the westward propagation of the equatorial SST annual cycle can be generated by the feedbacks of wind entrainment and evaporation with SST. Liu and Xie (1994) showed how the annual cycles along the Peru coast and in the southern subtropics propagate northwestward by wind-evaporation-SST feedback to impact the entire equatorial Pacific. The importance of the positive feedback between low-level stratus and SST on an annual cycle was investigated by $\mathrm{Yu}$ and Mechoso (1999). Li and Philander (1996) found that all the feedbacks of windupwelling-SST, wind-evaporation-SST, and low-level stratus-SST are important for the simulation of the annual cycle of the eastern Pacific in their coupled model.

Though the western propagation of the equatorial annual cycle has been attributed to the air-sea coupling by most of the previous studies (e.g., Horel 1982; Xie 1994; Chang and Philander 1994), Robertson et al. (1995) argued, from analyzing the output of their coupled general circulation model (GCM), that the westward propagation of zonal wind along the equatorial Pacific is remotely forced by the adjacent continental monsoons. Therefore, they suggested that the westward propagation of the SST annual cycle is a forced response to the westward-propagating zonal wind.
Considering the geographic proximity of the Asian and American continents to the tropical Pacific basin, the atmospheric heating associated with the Asian-Australian monsoons and American monsoons will definitely impact the circulations in the basin. How will these monsoons impact the mean state and annual cycle of the equatorial Pacific? Apparently, previous simple and intermediate coupled models are unsuitable to address this question because of their confined domain; almost all these models are limited to the tropical Pacific basin. The possible impacts of adjacent continental monsoons are either ignored or parameterized simply. In this study, we will add these continents into the Pacific-only, air-sea coupling system and address to what degree these adjacent continental monsoons will change the results of Pacific-only models, in terms of the mean state and annual cycle.

With an atmospheric GCM, Stone and Chervin (1984) assessed the contributions of zonal SST gradient along the equator and adjacent continental heating to driving the Walker circulation. Their results indicated that the equatorial trades are not simply driven by the SST gradient. The adjacent continental heating has significant influence on the strength of the trades. The observational studies of Krishnamurti (1985) and Murakami and Wang (1993) also implied that the Asian-Australian monsoons can change the surface winds of the tropical Pacific basin through a divergent planetary-scale atmospheric circulation.

An intermediate air-sea-land coupled model developed by Fu and Wang (2001) is used to assess the possible impacts of the adjacent continental monsoons and air-sea coupling on the mean state and annual cycle of the equatorial Pacific through controlled experiments. These experiments aim to address four questions: 1) How realistic are the mean state and annual cycle of the equatorial Pacific simulated by a Pacific-only, airsea coupled model? 2) Are the annual marches of the ITCZ/cold tongue complex self-sustained by the air-sea coupling? 3) If not, how and to what extent are they influenced by the Asian-Australian monsoons and American continental monsoons? 4) What is responsible for the westward propagation of equatorial SST annual cycle - the continental heating or air-sea coupling?

In the following section, a brief description of the coupled model and the experimental design are given. In section 3, we assess the impacts of the continental monsoons on the surface winds of the tropical Pacific with an atmosphere-only model. In section 4 , the influences of air-sea coupling and continental monsoons on the mean state and the annual cycle of equatorial Pacific are examined with a coupled model. Finally, our major results are summarized and the remaining uncertainties and further approaches are discussed in section 5 .

\section{Model \\ a. Model description}

An intermediate air-sea-land coupled model (Fu and Wang 2001) and its atmospheric component (Wang and 
Li 1993; Fu and Wang 1999) are used in this study. The atmospheric model is a $2 \frac{1}{2}$-layer, primitive equation model on the equatorial beta plane. It considers the interactions between the convective heating-forced free troposphere flows and the SST gradient-forced boundary layer flows. It also includes the effects of a cloudradiative forcing gradient on driving the tropical surface winds. The topographic effects are parameterized simply with the enhancement of boundary layer friction (Garratt 1977). The model atmosphere covers the global Tropics with lateral boundaries at $30^{\circ} \mathrm{S}$ and $30^{\circ} \mathrm{N}$. The standard horizontal resolution is $2^{\circ}$ latitude $\times 4^{\circ}$ longitude. In order to keep computational stability, a simulated backward scheme (Matsuno 1966) is used with a time increment of $30 \mathrm{~min}$. Radiational boundary conditions (Miller and Thorpe 1981) are used at the north and south boundaries to eliminate shortwave reflection. Because the model lateral boundaries are at $30^{\circ} \mathrm{S}$ and $30^{\circ} \mathrm{N}$, only the impacts of tropical monsoons are assessed here. The possible impacts from higher latitudes are deferred to further studies with global models.

The ocean component of the intermediate coupled model is an improved version of the tropical Pacific Ocean model originally developed by Wang et al. (1995). This ocean model comprises a mixed layer, in which the temperature and velocity are vertically uniform, and a thermocline layer in which temperature decreases linearly from the mixed layer base to the thermocline base. Both layers have variable depths. The deep ocean beneath the thermocline base is motionless with a constant reference temperature. The improved version of the ocean model uses the entrainment parameterization of Gaspar (1988), which treats the penetrated solar radiation in a more realistic fashion, and the momentum equations of McCreary and Yu (1992) for the mixed and thermocline layers. The explicit two-layer ocean dynamics results in more realistic simulations of the thermocline depth and ocean currents (Fu and Wang 2001). The ocean model extends from $120^{\circ} \mathrm{E}$ to $80^{\circ} \mathrm{W}$ with realistic but simplified east and west boundaries of the Pacific basin. The standard spatial resolution of the model is $1^{\circ}$ latitude $\times 2^{\circ}$ longitude, which requires an approximate time interval of $3 \mathrm{~h}$. No-flux conditions for temperature and no-slip conditions for velocities are applied at the coastal boundaries. To minimize the artificial effect of the northern and southern boundaries, the model temperature is relaxed back to the observed SST (Reynolds 1988).

Because our focus is on the equatorial Pacific climate, the active air-sea coupling is only allowed in the tropical Pacific Ocean. Outside the tropical Pacific, sea surface temperature is specified as the observed climatological monthly means (Reynolds 1988). Over land, surface temperature is the $1000-\mathrm{mb}$ air temperature from the European Centre for Medium-Range Weather Forecasts (ECMWF) 9-yr (1985-93) averaged monthly means. Clouds are specified in the coupled model. The data are the climatological monthly means from the International
Satellite Cloud Climatology Project (ISCCP; Rossow et al. 1988). The coarse vertical resolution of the atmospheric model makes it difficult to reasonably simulate the clouds by the model itself. Even in atmospheric GCMs, cloud simulation is still not satisfactory (Slingo and Slingo 1988; Philander et al. 1996; Schneider et al. 1997). To exploit the simplicity of an intermediate model, the trade-off we made is to specify the clouds. In fact, our sensitivity study shows that, when the clouds are fixed on the annual mean, the major characteristics of the simulated equatorial SST annual cycle [e.g., westward propagation, spring (fall) maximum (minimum) in the eastern Pacific and semiannual cycle in the western Pacific] are quite similar to the results including observed cloud annual cycle except that the amplitude is slightly smaller (Fu 1998).

In this coupled system, the atmospheric component exchanges information with the ocean component once per day. The atmosphere provides daily mean surface winds and heat fluxes to the ocean model. The latter send daily mean SST back to the former. In all the numerical experiments, the model is integrated for 10 yr. The last 4-yr output is averaged to get the model mean state and annual cycle. The initial atmospheric field is the perpetual steady response to the fixed SST on 1 January (interpolating from the monthly means in December and January) obtained with the atmosphereonly model. The initial ocean field is established in a similar way.

\section{b. Simulation of monsoons}

Rainfall associated with Asian-Australian monsoons and American monsoons is qualitatively simulated by this intermediate model. Figures 1a,b compare the annual mean rainfall and surface winds over the global Tropics in the observations and simulations. The observed rainfall is from the analysis of Xie and Arkin (1996). The observed surface winds are the 1000-mb winds from ECMWF analysis. The trades over the Pacific and Atlantic Oceans and flows over the Indian Ocean are captured. The major tropical rainfall centers over Africa, the Indian sector, the South Pacific convergence zone (SPCZ) the ITCZs, and America are picked up by the model. The obvious discrepancy occurs in the SPCZ, where the modeled rainfall extends too far eastward. This problem is commonly seen in the coupled GCMs (e.g., Schneider et al. 1997). The reasons for this error are unclear in our model and calls for further studies.

The annual variability of rainfall $P_{\text {var }}$ is estimated by

$$
P_{\mathrm{var}}=\sum_{i=1}^{12}\left[\left(P_{\mathrm{ri}}-P_{r}\right)^{2}\right]^{0.5 / 12}
$$

where $P_{\mathrm{ri}}$ is the individual monthly mean rainfall, $P_{r}$ is the annual mean rainfall. The observed and simulated annual rainfall variability in the Tropics is shown in 
(a) Surface Winds and Rainfall (Mean, OBS)
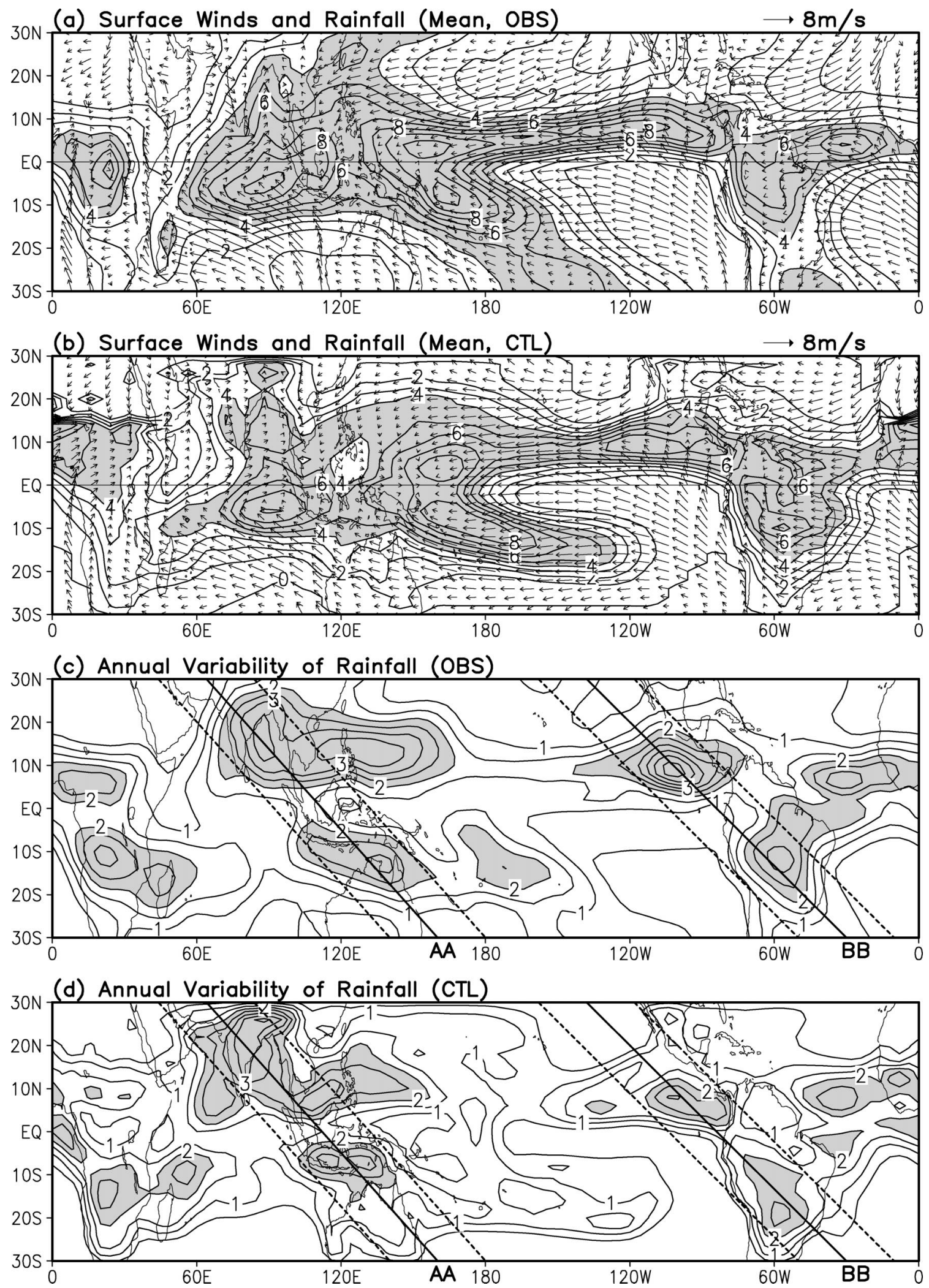

FIG. 1. (a) Observed, (b) simulated annual mean surface winds and rainfall ( $\left.\mathrm{mm} \mathrm{day}^{-1}\right)$; (c) observed, (d) simulated annual variability of rainfall over the global Tropics. The observed surface winds are the 1000-mb winds from the ECMWF analysis. The observed rainfall is from the Climate Prediction Center (CPC) Merged Analysis of Precipitation (CMAP) data (Xie and Arkin 1996). The simulations are from the coupled control run (CTL; Table 2) 
Figs. 1c,d. The major action centers of rainfall variability associated with the Asian-Australian monsoons and American monsoons are captured by the model. However, the simulated variability is smaller than the observations in some areas, for example, in the eastern North Pacific summer monsoon (ENPSM) just north of the cold tongue (Murakami et al. 1992; Wang 1994).

The annual marches of the observed and simulated Asian-Australian monsoons, represented as the total rainfall along the line AA (Figs. 1c,d) within $20^{\circ}$ longitude on each side, are shown in Figs. 2a,b. The model captures the essential annual evolution of the AsianAustralian monsoons in both magnitude and phase. In boreal winter, the monsoon rainfall axis moves to the Southern Hemisphere, corresponding to the onset of Australian summer monsoon. The simulated heaviest rainfall is located slight north of the observed. After April, associated with the annual warming of the Asian continent, heavy rainfall quickly shifts to the Northern Hemisphere and expands northward. However, the heaviest rainfall remains in the ocean around $10^{\circ} \mathrm{N}$. After August, the heaviest rainfall begins to retreat southward.

The observed rainfall annual variability in the global Tropics (Figs. 1c,d) shows that tropical American monsoons primarily comprise the boreal summer rainfall over the ENPSM and the austral summer rainfall in the South American continent (Horel et al. 1989). Therefore, the rainfall within $20^{\circ}$ longitude of the line $\mathrm{BB}$ is used to represent the annual evolution of tropical American monsoons. The annual variations of simulated rainfall from $30^{\circ} \mathrm{S}$ to $30^{\circ} \mathrm{N}$ are compared with the observations in Figs. 2c,d. From November to the following March is the wet season of South America. The heavy rainfall is located between $5^{\circ}$ and $15^{\circ} \mathrm{S}$. During March and April, the heavy rainfall axis moves to the Northern Hemisphere. The associated rainfall between $5^{\circ}$ and $10^{\circ} \mathrm{N}$ quickly intensifies following the seasonal march and approaches the maximum in early summer (June or July). The corresponding rainfall in boreal summer is primarily in the Pacific Ocean over the ENPSM region. Only a small portion is over Central and North America. The boreal summer monsoons span April-November with the maximum rainfall around $8^{\circ} \mathrm{N}$. In November, the heaviest rainfall jumps abruptly from $7^{\circ} \mathrm{N}$ to about $10^{\circ} \mathrm{S}$, representing the rapid onset of the South American summer monsoon. Compared to the observations, the simulated rainfall in the ENPSM is weaker. The modeled onset of the South American summer monsoon is one month ahead.

Overall, the annual mean rainfall centers over Africa, the Indian sector, the SPCZ, the ITCZs, and America are captured by the model. The simulated annual marches of rainfall associated with the Asian-Australian monsoons and American monsoons are comparable with the observations. This coupled model also realistically simulates the annual means and annual cycles of the key variables (e.g., SST, surface winds, mixed layer depth, and currents) in the tropical Pacific, especially in the equatorial region. The details have been reported in $\mathrm{Fu}$ and Wang (2001). The results of this coupled run will be referred to as the coupled control run (CTL; Table 2 ) in the following analysis.

\section{c. Experimental design}

Two sets of numerical experiments are conducted with the atmospheric model and the coupled model. They are summarized in Tables 1 and 2, respectively. With the atmospheric model, five controlled experiments [the atmospheric control run (ACTL), the atmospheric Pacific-only (APAC), the Asian-Australian summer monsoon (AASM), the atmospheric North American monsoon (ANAM), and the atmospheric South American monsoon (ASAM); Table 1] have been carried out to assess the remotely forced surface winds over the tropical Pacific basin by the adjacent continental monsoons. Similarly, the other five experiments with the coupled model [the coupled control run (CTL), the Pacific-only coupling run (PAC), the Australian summer monsoon (ASM), the North American monsoon (NAM), and the South American monsoon (SAM); Table 2] have been conducted to estimate the roles of each individual monsoon on rectifying the mean state and regulating the annual cycle of the equatorial Pacific SST.

The ACTL represents an atmospheric control run. In this experiment the observed monthly mean clouds are specified over the global Tropics; the observed monthly mean surface temperatures are specified outside the $\mathrm{Pa}$ cific. Inside the Pacific, the SST is taken from the output of the coupled control run (CTL; Table 2). Therefore, the simulated climate of rainfall and surface winds in the ACTL is nearly the same as that in the CTL. In the APAC, the monthly mean external forces (surface temperature and clouds) are only allowed in the tropical Pacific region. Outside the Pacific annual mean external forces are specified. In the AASM, the monthly mean external forces are used in both the Pacific and AsianAustralian regions. The ANAM adds the monthly mean external forces in the North America based on the AASM. Finally, in the ASAM the monthly mean forces are added in South America based on the ANAM. Though the atmospheric responses to the external forces in this model are not exactly linear, the consistence of the results from the atmospheric control run (ACTL) and the coupled control run (CTL; figure not shown) suggests that the transient processes do not change the monthly mean much in this model. Therefore, in the following analysis, the difference between the ACTL and the APAC will be attributed to the impacts of all adjacent continental monsoons. The difference between the AASM and APAC is due to the Asian-Australian monsoons and so on. Because the coupled experiments are just a parallel of the atmosphere-only experiments, details are not repeated here. 
(a) Asian-Australian Monsoon (OBS, Xie\&cArkin 1996)

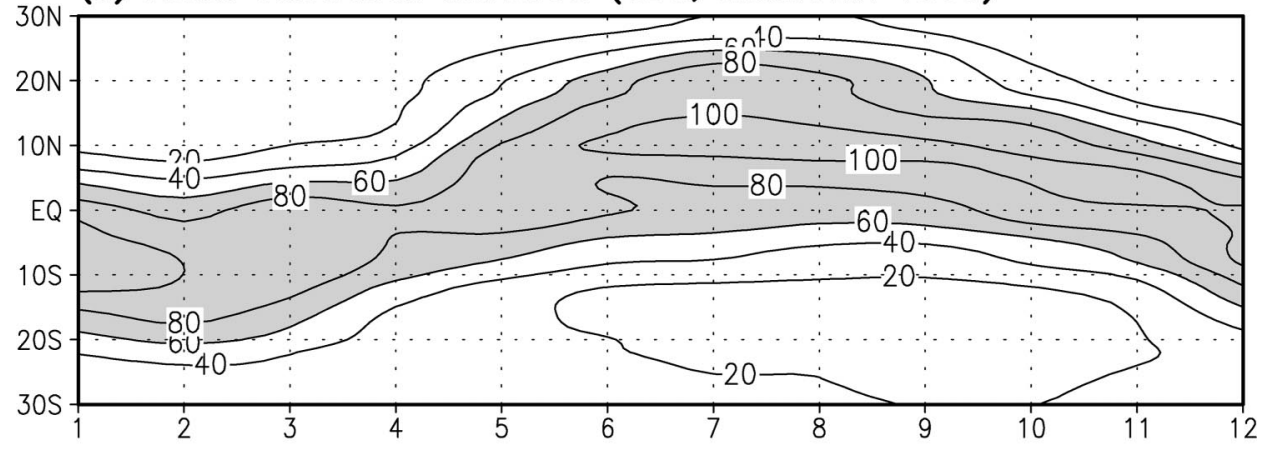

(b) Asian-Australian Monsoon (CTL)
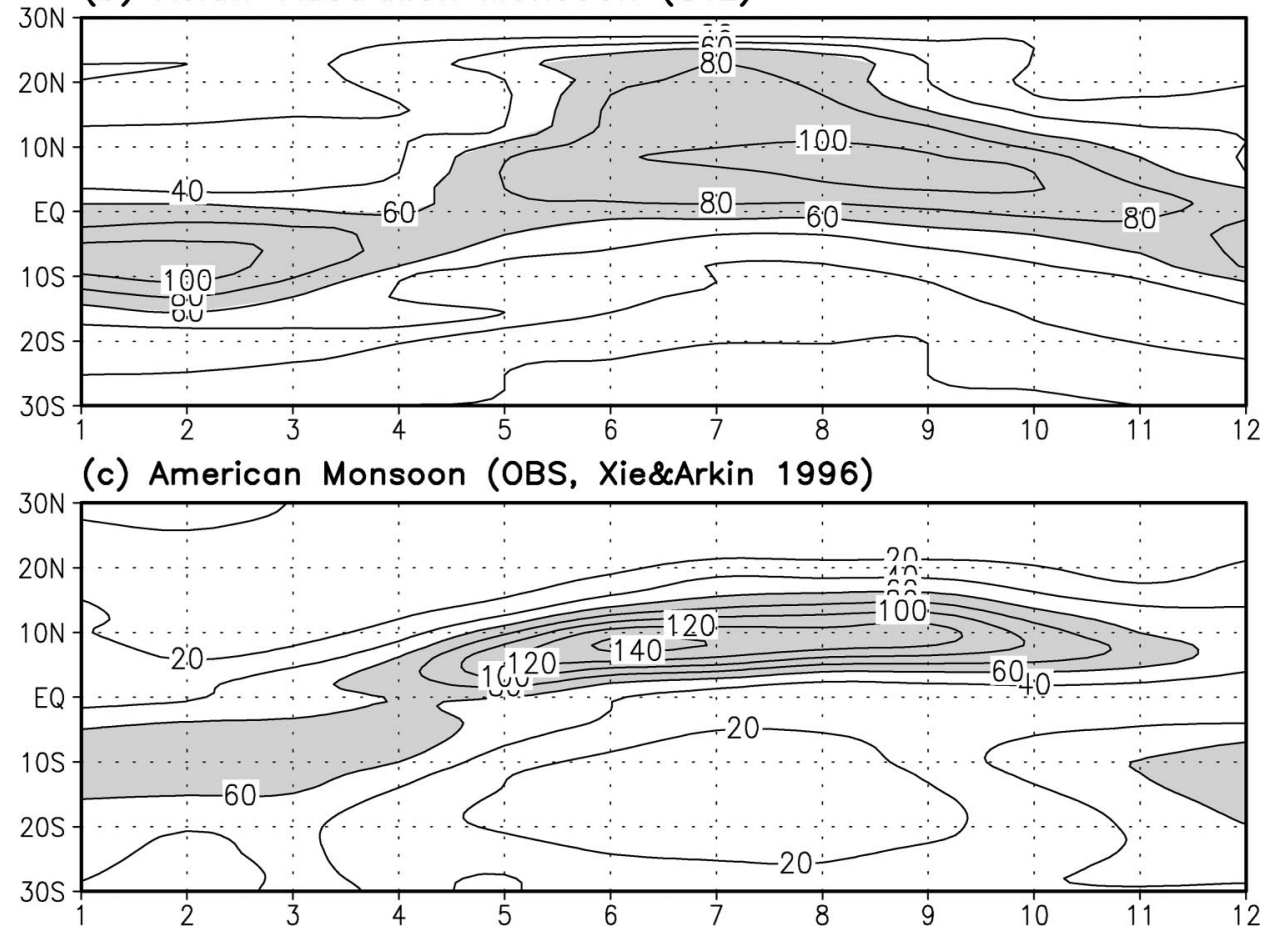

(d) American Monsoon (CTL)

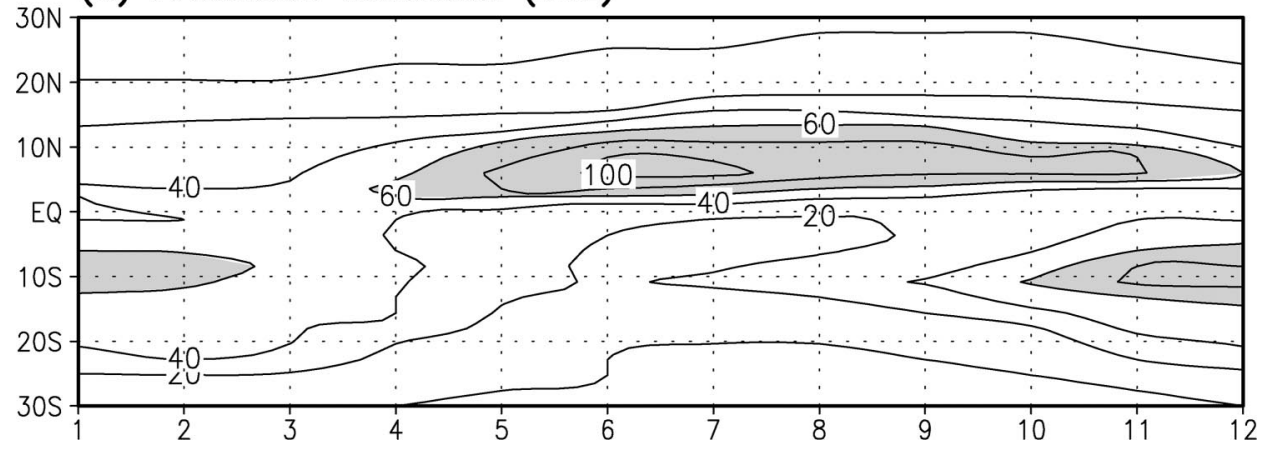

FIG. 2. (a) Observed, (b) simulated annual variations of rainfall $\left(\mathrm{mm} \mathrm{day}^{-1}\right)$ for the Asian-Australian monsoons; (c) observed, (d) simulated annual variations of rainfall $\left(\mathrm{mm} \mathrm{day}^{-1}\right)$ for the American monsoons. The observed rainfall is from the CMAP data (Xie and Arkin 1996). The simulations are from the coupled control run (CTL; Table 2). 
TABLE 1. Five experiments with an atmosphere-only model.

\begin{tabular}{lll}
\hline \hline Labels & \multicolumn{1}{c}{ Monthly mean forces* } & Annual mean forces \\
\hline ACTL & Global Tropics & No \\
APAC & Tropical Pacific & Outside the tropical Pacific \\
AASM & Tropical Pacific + Asian-Australian region $\left(40^{\circ} \mathrm{E}-\right.$-west coast of Pacific $)$ & Other tropical region \\
ANAM & The above region + tropical North American continent $\left(0^{\circ}-30^{\circ} \mathrm{N}\right)$ & Other tropical region \\
ASAM & The above region + tropical South American continent $\left(30^{\circ} \mathrm{S}-0^{\circ}\right)$ & Other tropical region \\
\hline
\end{tabular}

* Forces include surface temperature and clouds. SST in the tropical Pacific is the long-term mean from the coupled control run (CTL; Table 2); surface temperature outside the tropical Pacific is the 1000-mb air temperature (ECMWF) over land and the observed SST (Reynolds 1988) over oceans; the clouds are from the ISCCP dataset.

\section{Results of atmosphere-only experiments}

\section{a. Annual mean and variability}

Figure 3 a shows the impacts of the adjacent continental monsoons on the annual mean of surface winds in the tropical Pacific. The primary influence is the increase of the trades over the western Pacific. However, the magnitude is smaller than $1 \mathrm{~m} \mathrm{~s}^{-1}$ except in the far western tropical Pacific. This wind perturbation is primarily caused by the diabatic heating over the Indian sector associated with the Asian-Australian monsoon rainfall (Fig. 4). Figure 3b shows that the annual variability of the surface winds is increased in both the western and eastern Pacific by the monthly mean forces outside the Pacific. Comparison of Figs. $3 \mathrm{a}$ and $3 \mathrm{~b}$ suggests that the Asian-Australian monsoons act to change both the annual mean and annual variability of surface winds in the western Pacific. However, the American continental monsoons may only affect the annual variations of the surface winds in the eastern Pacific, but not the annual mean.

\section{b. Annual cycle along the equator}

Figure 5a shows the annual cycle of the equatorial zonal wind driven by all the adjacent continental monsoons outside the Pacific. No apparent westward propagation as suggested by Robertson et al. (1995) is observed in this figure. The Asian-Australian monsoons force a significant annual cycle of zonal wind in the western Pacific (Fig. 5b). The North American continental monsoon indicates little influence on the equatorial zonal wind (Fig. 5c). On the other hand, the South American continental monsoon considerably enhances (reduces) the easterly trades in the eastern equatorial Pacific from April to September (from October to the following March; Fig. 5d). The annual phase changes of the zonal winds are nearly simultaneous along the equator and no westward-propagating signal is found. The effects of these remotely forced zonal winds on the equatorial SST annual cycle will be examined later with a coupled model.

\section{c. In the eastern Pacific}

\section{1) ONSET OF THE ENPSM}

Rainfall increases rapidly from March to May in the eastern North Pacific (Fig. 6a) as indicated by Murakami et al. (1992) and Mitchell and Wallace (1992). This period symbolizes the onset of the ENPSM. Mitchell and Wallace (1992) have speculated that the northward movement of the Central American (Colombia and Panama) monsoon convection from the equatorial belt into the Northern Hemisphere extends westward into the warm pool along $9^{\circ} \mathrm{N}$ to form the oceanic ITCZ (the ENPSM) in May. However, close examination of the annual variations of rainfall (Wang 1994) indicates no lag between the onset of rainy seasons over the open ocean and the Central American continent. Wang (1994) instead speculated that it was the cooling of the equatorial cold tongue triggering the onset of the ENPSM. The similarity of the rainfall and circulation in the eastern North Pacific in the ACTL (Fig. 6a) and the APAC (Fig. 6b) supports that the onset of the ENPSM does not directly depend on the Central American continental monsoon, because there is no annually varying force at all over the tropical American continent in the APAC experiment.

TABLE 2. Five experiments with a coupled model.

\begin{tabular}{lll}
\hline \hline Labels & \multicolumn{1}{c}{ Monthly mean forces* } & Annual mean forces \\
\hline CTL & Global Tropics & No \\
PAC & Tropical Pacific & Outside the tropical Pacific \\
ASM & Tropical Pacific + Asian-Australian region $\left(40^{\circ} \mathrm{E}-\right.$-west coast of Pacific $)$ & Other tropical region \\
NAM & The above region + tropical North American continent $\left(0^{\circ}-30^{\circ} \mathrm{N}\right)$ & Other tropical region \\
SAM & The above region + tropical South American continent $\left(30^{\circ} \mathrm{S}-0^{\circ}\right)$ & Other tropical region \\
\hline
\end{tabular}

* Forces include surface temperature and clouds. SST in the tropical Pacific is produced by the coupled model; surface temperature outside the tropical Pacific is the 1000-mb air temperature (ECMWF) over land and the observed SST (Reynolds 1988) over oceans; the clouds are from the ISCCP dataset. 
(a) Diff. of Mean Surface Winds (ACTL-APAC)

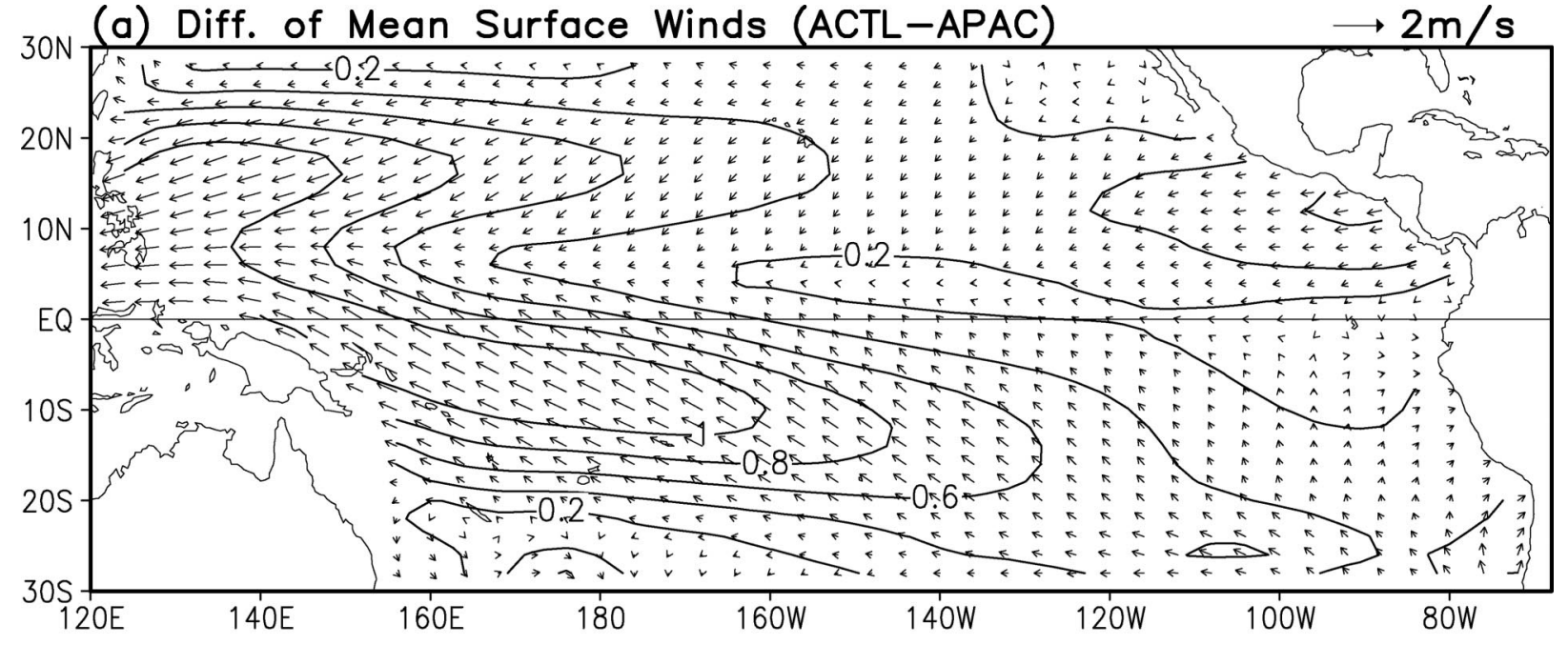

(b) Diff. of Annual Variability of Surface Winds (ACTL-APAC)

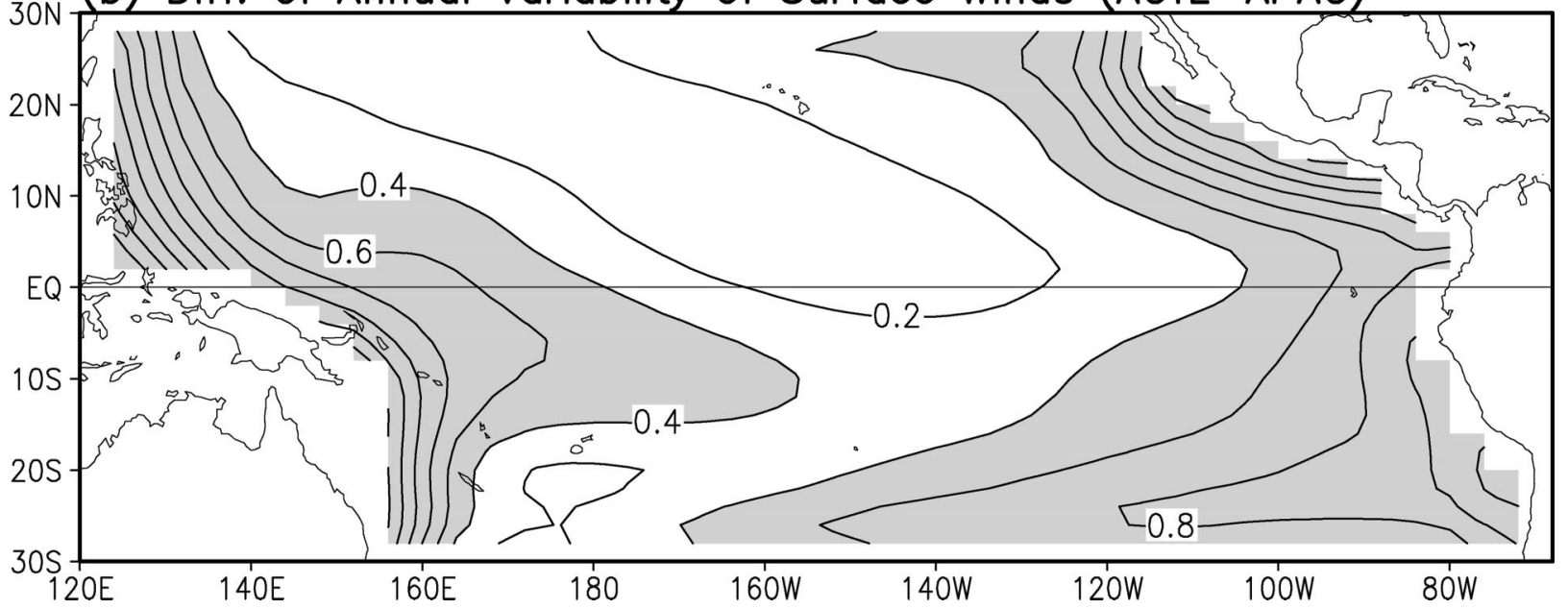

FIG. 3. (a) The difference of the annual mean surface winds (the contours show the wind speed with a $0.2 \mathrm{~m} \mathrm{~s}^{-1}$ interval); (b) difference of the annual variability of surface wind speed (contour interval of $0.2 \mathrm{~m} \mathrm{~s}^{-1}$ ) between the atmosphere-only control run (ACTL; Table 1) and the run without adjacent continental monsoons (APAC; Table 1).

In order to estimate the relative importance of the ITCZ warming and the cold tongue cooling on the onset of the ENPSM, two more experiments are conducted. In the "ITCZ" experiment, only the monthly mean forces (SST and clouds) in the ITCZ $\left(4^{\circ}-10^{\circ} \mathrm{N}\right.$, $140^{\circ} \mathrm{W}$-American coast) region are allowed. In the "CT" experiment, the monthly mean forces (SST and clouds) are activated only in the cold tongue region, which is confined to a triangle area, enclosed by two straight lines from $2^{\circ} \mathrm{N}, 140^{\circ} \mathrm{W}$ to $30^{\circ} \mathrm{S}, 80^{\circ} \mathrm{W}$ and $2^{\circ} \mathrm{N}$, $78^{\circ} \mathrm{W}$, and the west coast of America. The differences of surface winds and rainfall between May and March from these two experiments are shown in Figs. $6 \mathrm{c}$ and $6 \mathrm{~d}$, respectively. The results, apparently, suggest that the onset of the ENPSM is primarily due to the ITCZ warming, rather than the cooling of the cold tongue.
2) Surface winds associated with the REESTABLISHMENT OF THE COLD TONGUE

The sea surface temperature in the eastern Pacific cold tongue (EPCT; $\left.4^{\circ} \mathrm{S}-2^{\circ} \mathrm{N}, 120^{\circ}-90^{\circ} \mathrm{W}\right)$ approaches its annual maximum in March and April. The early reestablishing stage of the EPCT occurs from March to May (Mitchell and Wallace 1992; Nigam 1997; Wang and Fu 2001). The possible impacts of the adjacent continental monsoons on the surface winds in the eastern Pacific between March and May are explored in the following paragraph.

Figure 7a shows the changes of surface winds from March to May over the central-eastern Pacific driven by the annually varying forces outside the Pacific. As indicated before, the influences of the Asian-Australian monsoons are primarily limited to the western Pacific. 


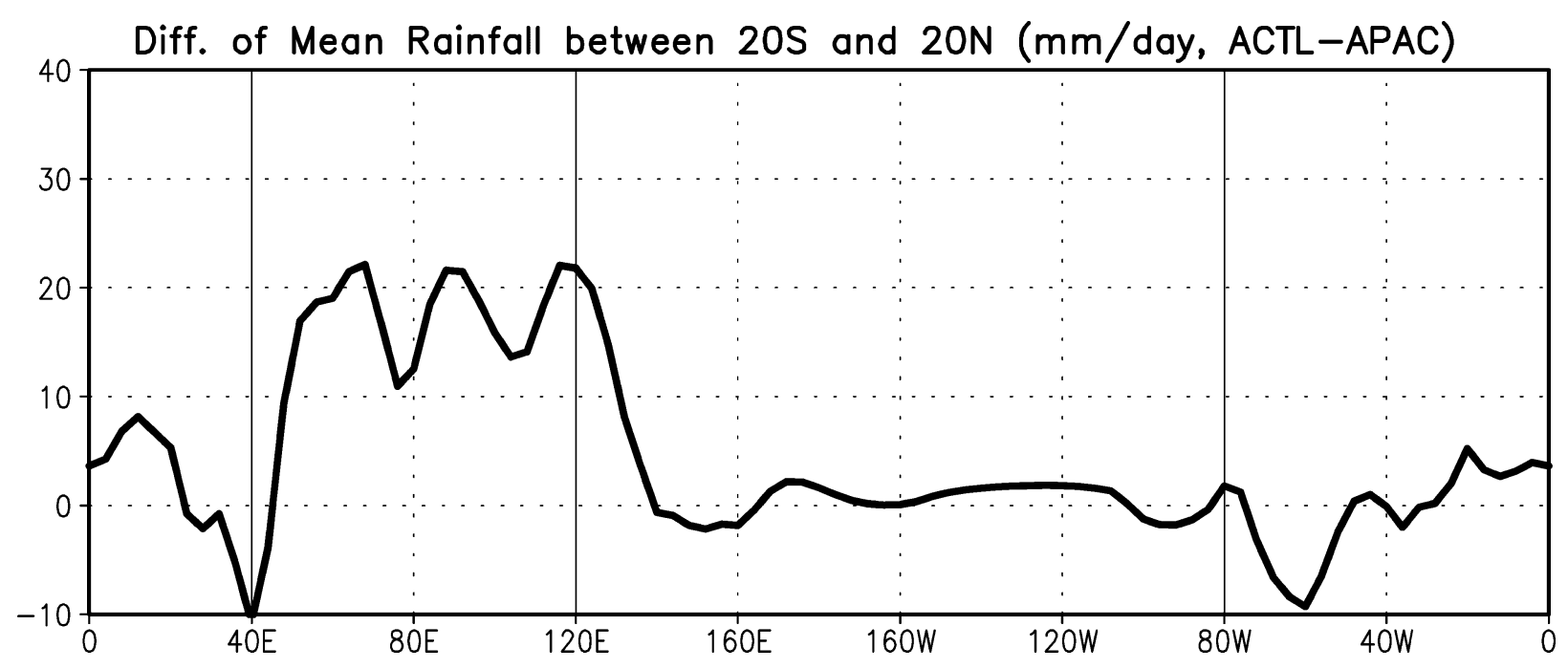

FIG. 4. The difference of the annual mean rainfall in the equatorial belt $\left(20^{\circ} \mathrm{S}-20^{\circ} \mathrm{N}\right)$ between two experiments (ACTL - APAC; Table 1).

The surface wind perturbations in the eastern Pacific are basically caused by the American continental monsoons. The respective impacts from tropical North America $\left(0^{\circ}-30^{\circ} \mathrm{N}\right)$ and tropical South America $\left(0^{\circ}-30^{\circ} \mathrm{S}\right)$ are shown in Figs. 7b,c. The diabatic heating associated with the onset of the North American continental monsoon only causes a small southwest wind perturbation in the northern subtropics. The stronger southeast trades in the EPCT are driven by the diabatic cooling associated with the northward retreat of the South American summer monsoon from March to May. This implies that the South American monsoon has larger impacts in the EPCT than the North American continental monsoon. These circulation responses to the diabatic heating/cooling in tropical North and South America are consistent with the results of Nigam (1997), who forces an atmospheric general circulation model with the diagnostic diabatic heating/cooling sources. He also showed that the diabatic cooling over South America enhances the southeast trades in the eastern Pacific. The enhanced southeast trades may contribute to the rapid reestablishment of the EPCT from March to May. This will be tested in the next section with an air-sea coupled model.

\section{Results of coupled experiments}

The annual mean SST in the tropical Pacific and the annual cycle along the equator from the PAC (Table 2) have been compared with the results from the CTL (Table 2; Fig. 8). The mean SST fields from the CTL and PAC (Figs. 8a,b) look similar, in terms of the equatorial warm pool/cold tongue structure and the ITCZ/cold tongue complex in the eastern Pacific. However, without the effects of the adjacent continental monsoons (PAC), the warm pool shifts to the central Pacific and the trades are too weak in the western Pacific (Fig. 9). The dominant annual cycle in the east and westward propagation of equatorial SST are both captured by the PAC (Fig. 8d). However, compared to the CTL (Fig. 8c), the amplitude of the SST annual cycle in the PAC is halved. The coldest phase occurs around November-December (at $100^{\circ} \mathrm{W}$ ), which is a $2-3$-month lag of the control run. In the western Pacific, particularly between $140^{\circ}$ and $160^{\circ} \mathrm{E}$, a fictitious annual cycle is produced, dissimilar to the semiannual cycle in the control run and the observations.

\section{a. Rectification on the mean state}

The adjacent continental monsoons are able to rectify the mean state of the tropical Pacific. Figures 10a,b show the annual mean differences of SST and surface winds between the CTL and the PAC. The SST in the CTL is systematically lower than that in the PAC, because the easterly in the CTL run is stronger than that in the PAC (Fig. 10b), which increases the entrainment, surface evaporation, and westward cold advection. The enhanced easterly in the CTL run also deepens the thermocline in the western Pacific and lifts it in the eastern Pacific (Fu and Wang 2001). The latter is responsible for the eastward extension of the cold perturbations (Fig. 10a). As shown in section 3a, the diabatic heating associated with the Asian-Australian monsoons forces an easterly through a Kelvin wave response (Gill 1980) in the western-central Pacific, thus resulting in better simulation of SST there (Fig. 9a). The SST anomaly (Fig. 10a) is not just a passive response to the remotely forced surface winds. The obviously stronger trades in the coupled run (Fig. 10b), than those in the atmosphere-only run (Fig. 3a), suggest that the air-sea coupling is involved in this rectifying process.

\section{b. Annual cycle along the equator}

\section{1) Westward PROPAgation OF SST}

Figure 11 shows the annual cycles of SST and zonal wind along the equator caused by the North and South 
(a) Diff. of EQ $\cup$ Annual Cycle (ACTL-APAC)

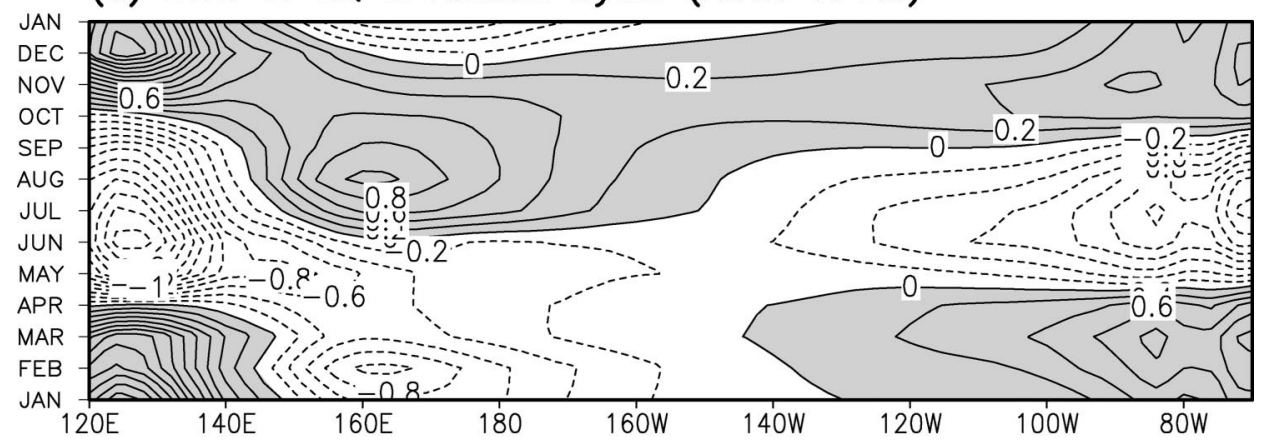

(b) Diff. of EQ $\cup$ Annual Cycle (AASM-APAC)

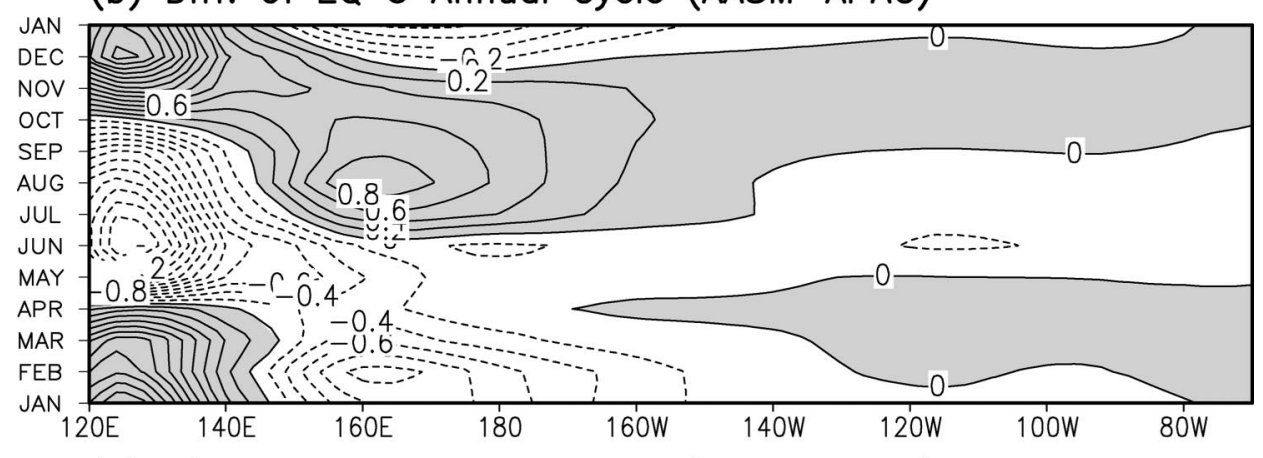

(c) Diff. of EQ $\cup$ Annual Cycle (ANAM-AASM)

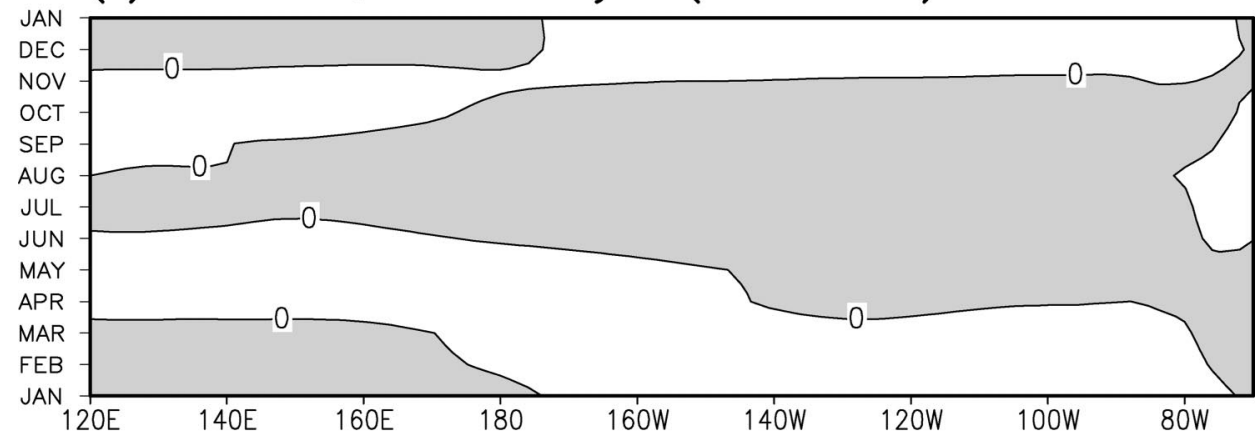

(d) Diff. of EQ $U$ Annual Cycle (ASAM-ANAM)

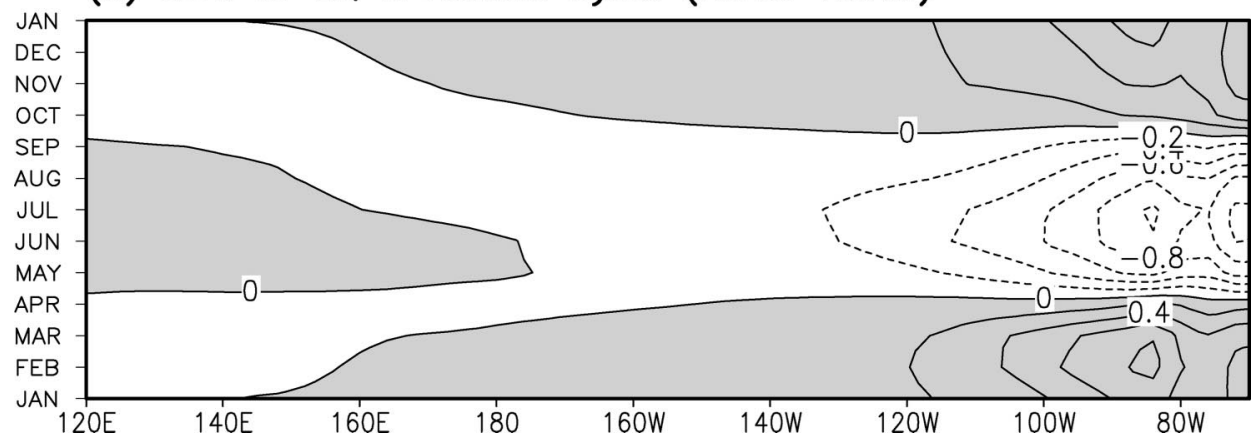

FIG. 5. The annual perturbations of remotely forced equatorial zonal winds $\left(\mathrm{m} \mathrm{s}^{-1}\right)$ by (a) all adjacent continental monsoons (ACTL - APAC), (b) by the Asian-Australian monsoons (AASM - APAC), (c) by the North American continental monsoons (ANAM - AASAM), (d) by the South American continental monsoons (ASAM - ANAM). Detailed explanations of the experiments (ACTL, APAC, AASM, ANAM, and ASAM) are given in Table 1. The contour interval is $0.2 \mathrm{~m} \mathrm{~s}^{-1}$ with westerly perturbations shaded. 
(a) Diff. of Surface Wind and Rainfall (ACTL, May-March)

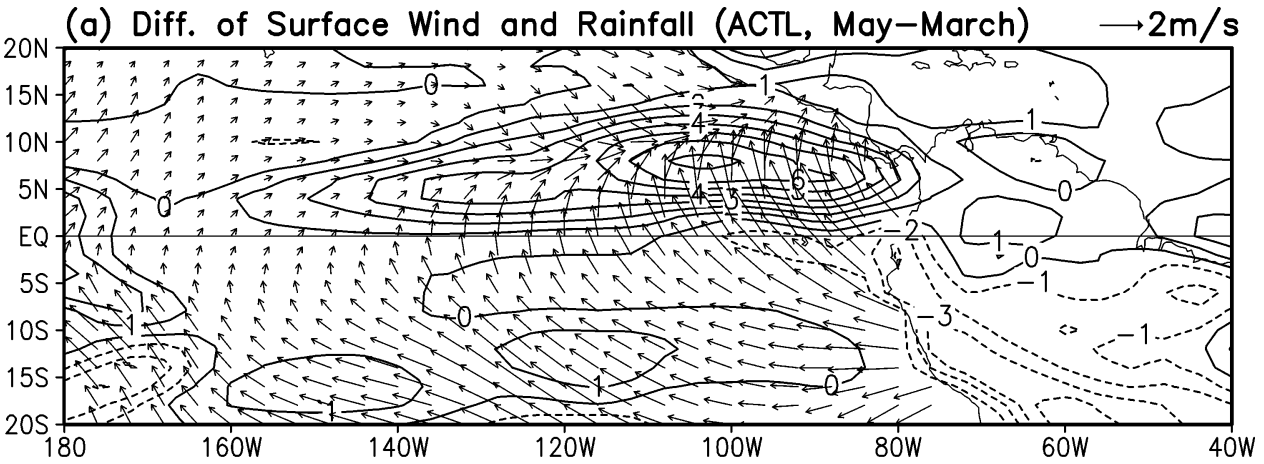

(b) Diff. of Surface Wind and Rainfall (APAC)

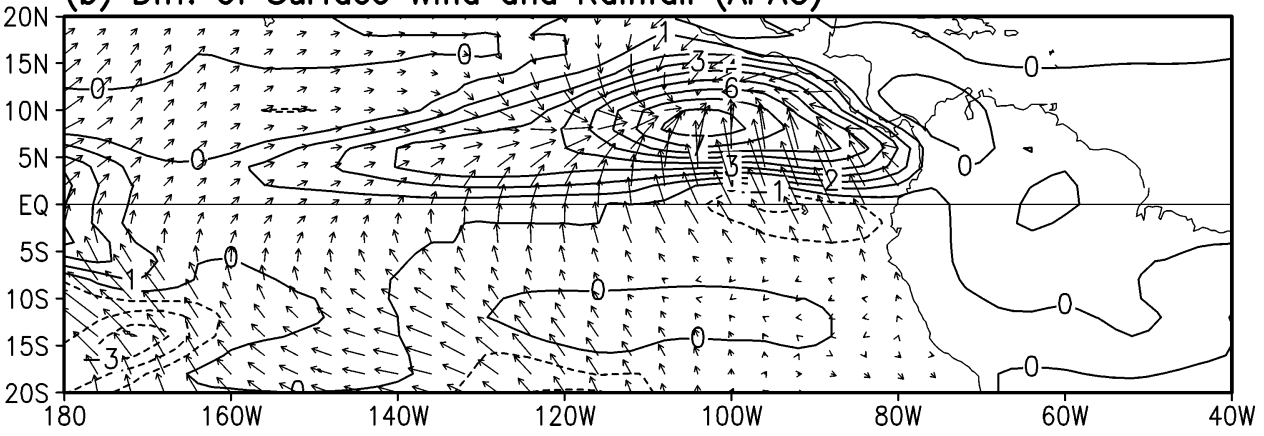

(c) Diff. of Surface Wind and Rainfall (ITCZ)

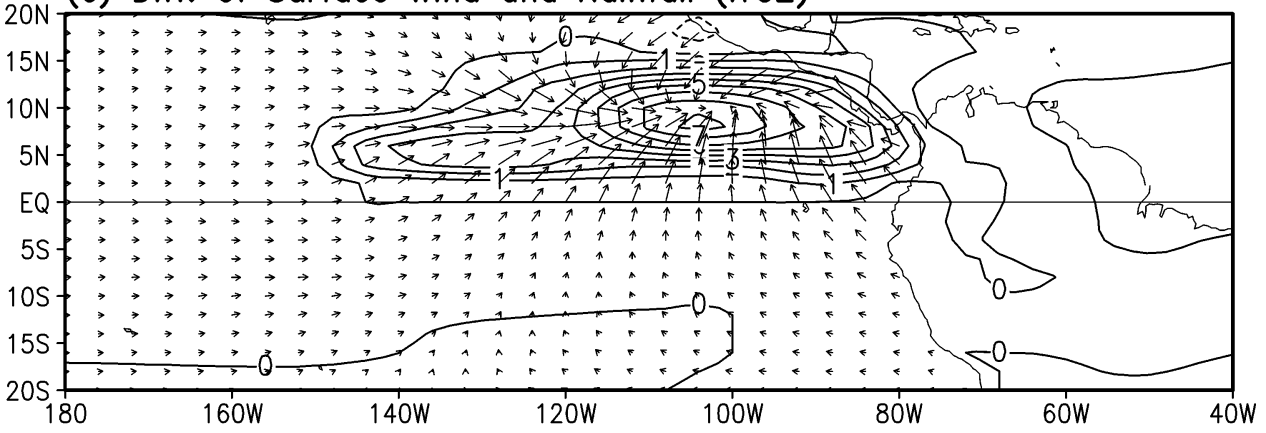

(d) Diff. of Surface Wind and Rainfall (CT)

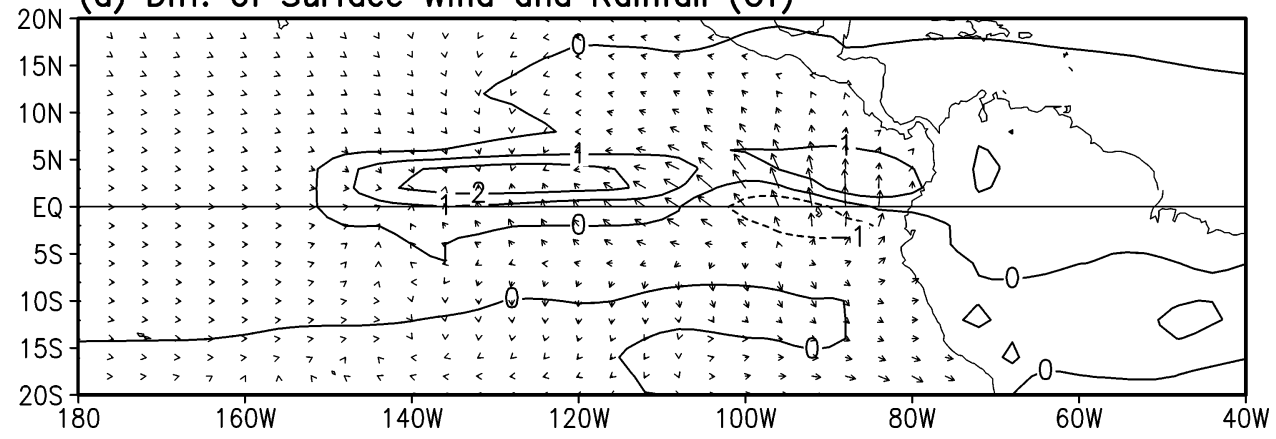

FIG. 6. The changes of surface winds and rainfall from Mar to May; (a) in the atmosphere-only control run (ACTL; Table 1), (b) without all adjacent continental monsoons (APAC; Table 1), (c) with annually varying forces in the eastern ITCZ only (ITCZ), (d) with annually varying forces in the cold tongue only (CT). More details about the ITCZ and CT experiments can be found in the text. The contour interval is 1 $\mathrm{mm} \mathrm{day}^{-1}$. 
(a) Diff. of Surface Wind and Rainfall (ACTL-APAC)

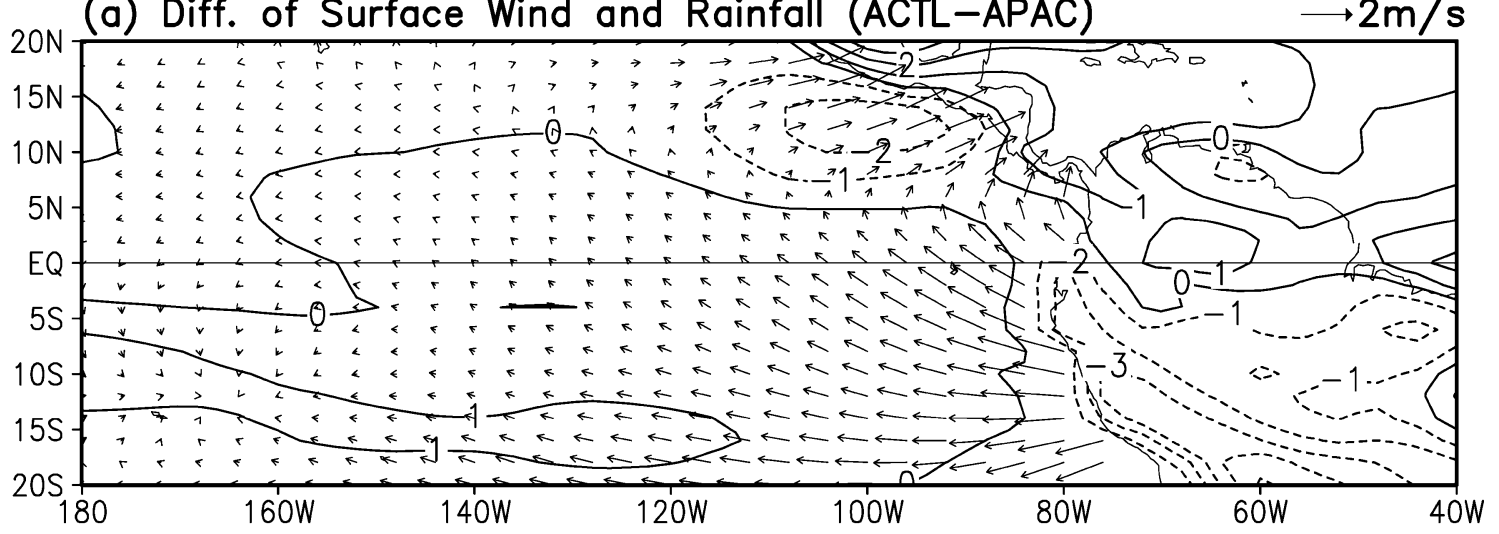

(b) Diff. of Surface Wind and Rainfall (ANAM-AASM)

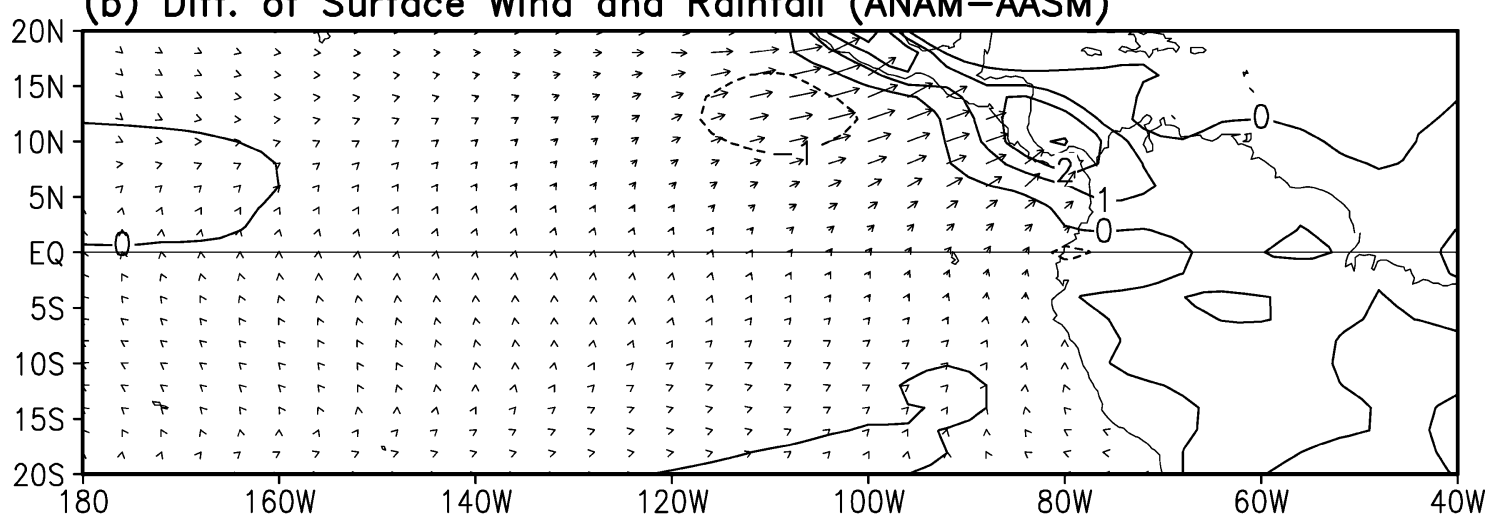

(c) Diff. of Surface Wind and Rainfall (ASAM-ANAM)

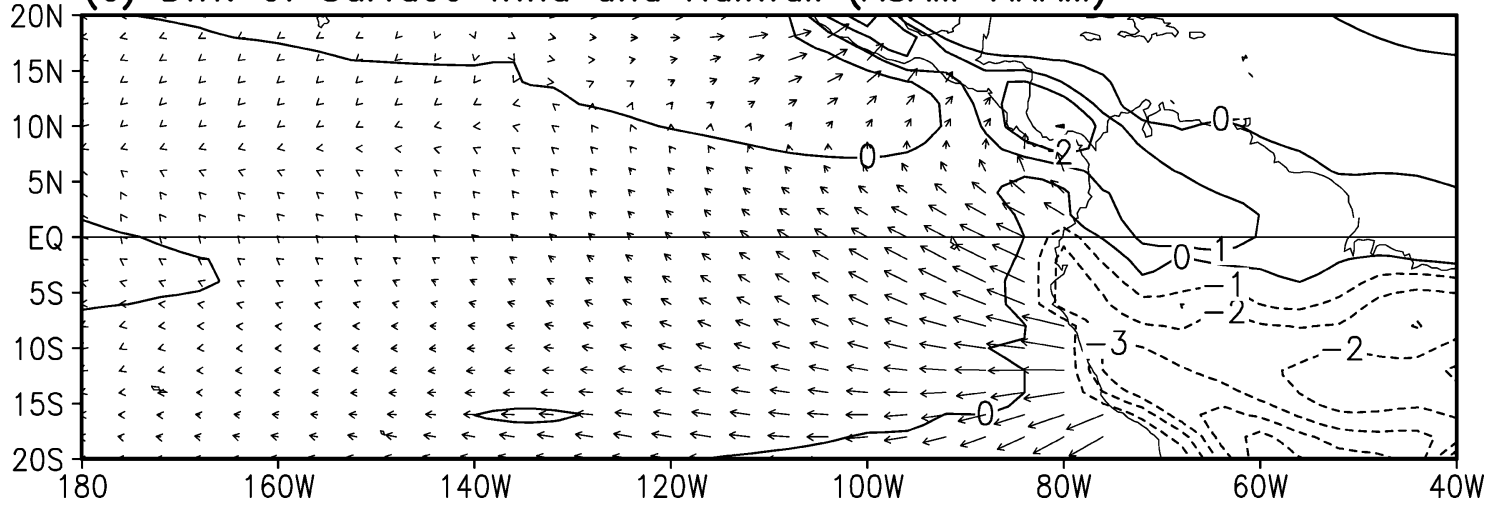

FIG. 7. The changes of surface winds and rainfall from Mar to May caused by (a) the American continental monsoons (ACTL - APAC), (b) by the North American continental monsoons (ANAM - AASM), (c) by the South American monsoons (ASAM - ANAM). Detailed explanations of the experiments (ACTL, APAC, AASM, ANAM, and ASAM) are in Table 1. The contour interval is $1 \mathrm{~mm} \mathrm{day}^{-1}$.

American continental monsoons. From Figs. 11a,b, we see that the North American continental monsoons have little influence on the annual cycles of the equatorial SST and zonal wind. On the other hand, the South American monsoon causes a westward-propagating warm perturbation from January to June with a peak in April and a cold perturbation in the other months peaking in September over the eastern Pacific (Fig. 11c). The perturbations of the SST lag the perturbations of surface zonal wind by about 2 months (Figs. 11c,d).
From April to October, accompanying the South American continental winter monsoon, an easterly perturbation is generated in the eastern Pacific (Zhou and Lau 1998; Nigam 1997). This perturbation approaches the maximum in June and July. Associated with the occurrence of the South American summer monsoon in the other months, an equatorial westerly perturbation is produced. The maximum westerly perturbation in the eastern Pacific occurs in February and March.

Both the perturbations of SST and zonal wind prop- 
(a) Annual Mean SST (CTL)

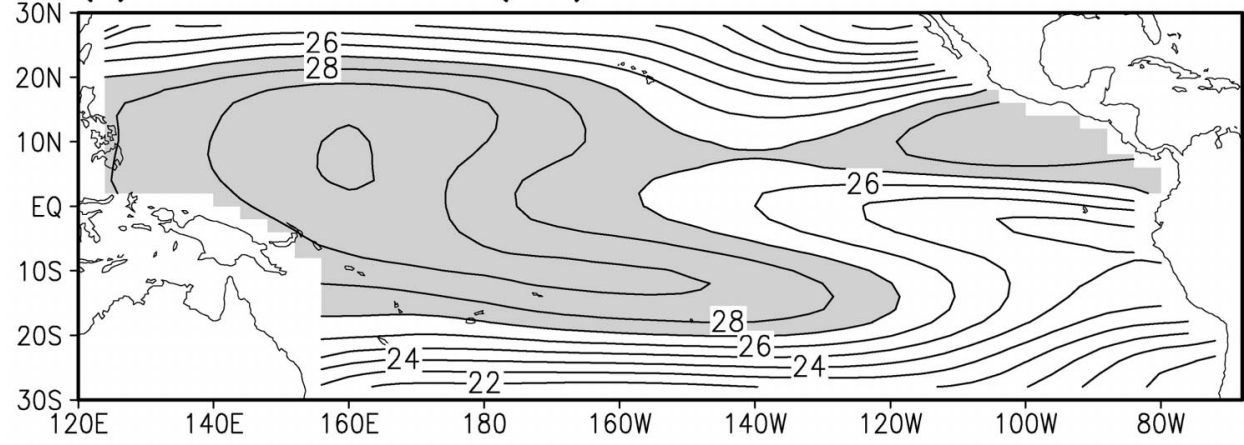

(b) Annual Mean SST (PAC)

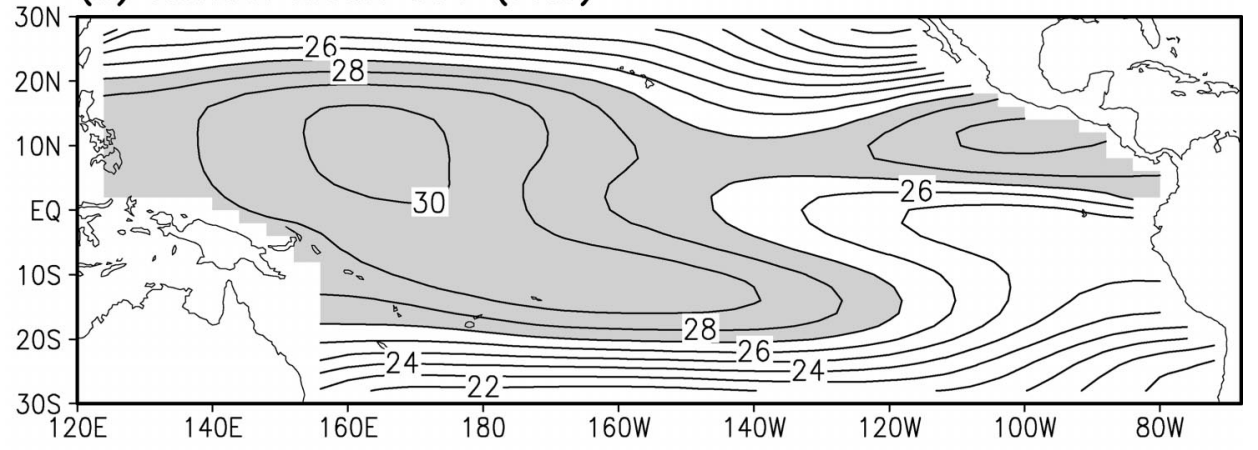

(c) EQ SST Annual Cycle (CTL)
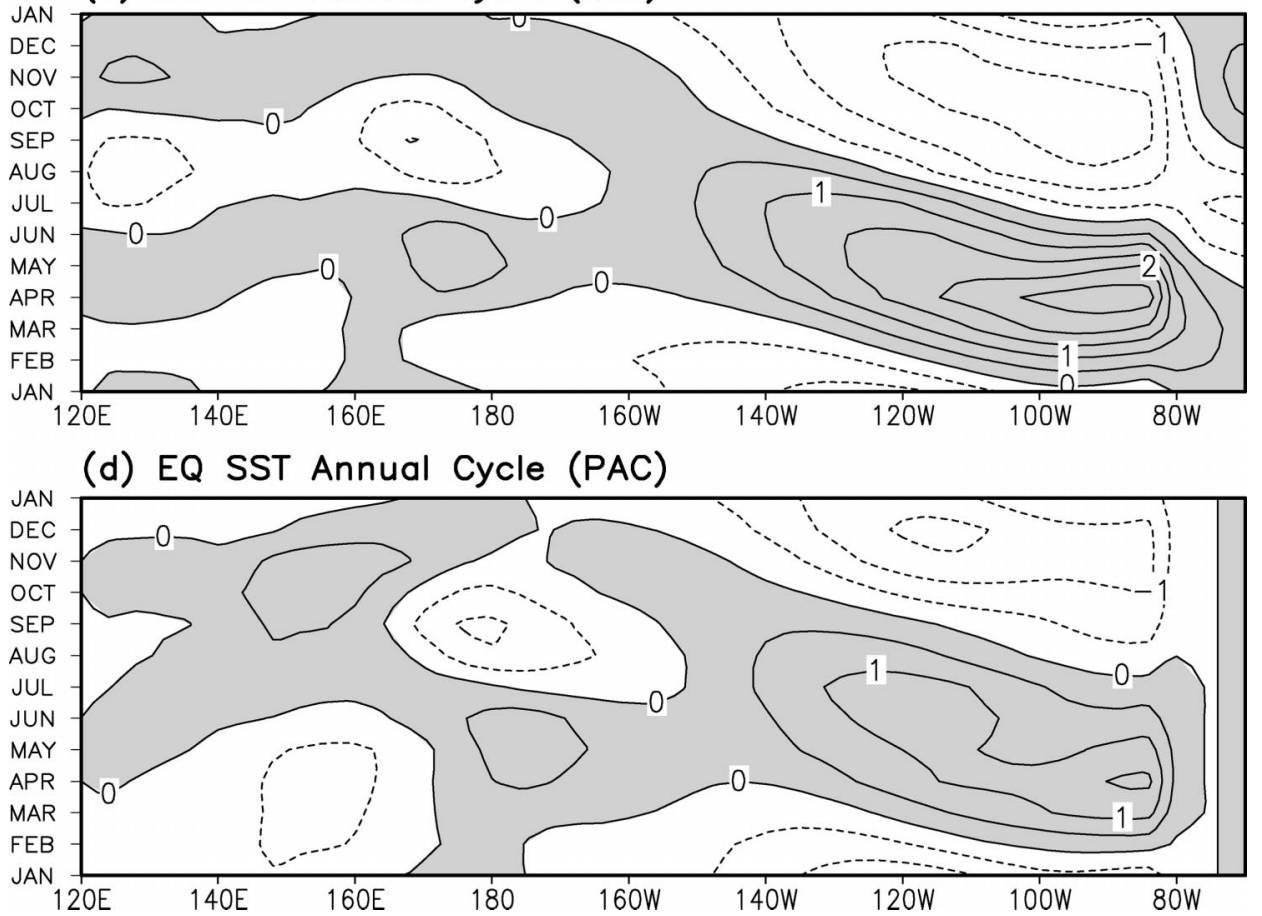

FIG. 8. The annual mean SST (a) in the coupled control run (CTL; Table 2), (b) without all adjacent continental monsoons (PAC; Table 2). The contour interval is $1{ }^{\circ} \mathrm{C}$ with SST higher than $27^{\circ} \mathrm{C}$ shaded. The SST annual cycle along the equator (c) from the coupled control run (CTL), (d) without all adjacent continental monsoons (PAC). The contour interval is $0.5^{\circ} \mathrm{C}$ with positive SST perturbations shaded. 
(a) Mean Equatorial SST (C)

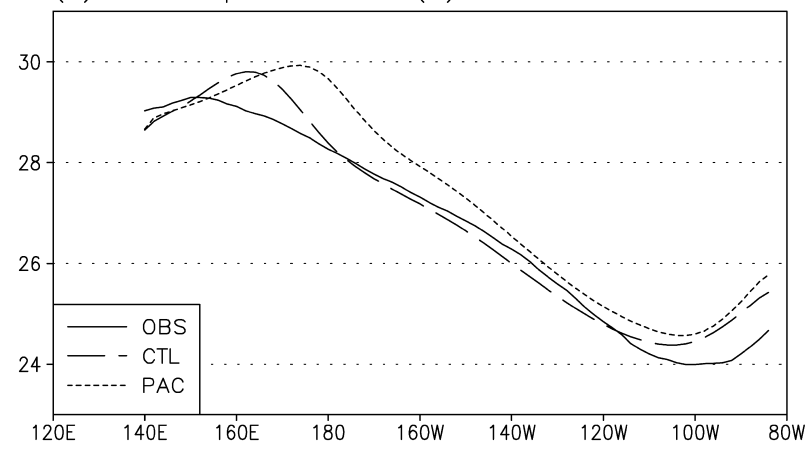

(b) Mean Equatorial Zonal Wind ( $\mathrm{m} / \mathrm{s}$ )

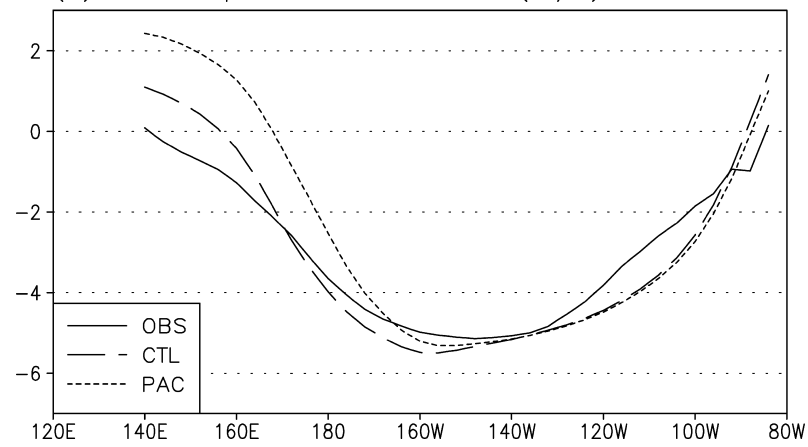

FIG. 9. The annual mean equatorial Pacific (a) SST and (b) zona winds from the observations (OBS, solid lines) and simulated by the coupled model in the control run (CTL, dashed) and without adjacent continental monsoons (PAC, dotted).

agate westward along the equator (Figs. 11c,d). Because no westward propagation of zonal wind was found in the atmosphere-only experiment (Fig. 5d), the westward propagation of the zonal wind in this case is due to airsea coupling. The heat budget analysis of oceanic mixed layer by $\mathrm{Fu}$ and Wang (2001) suggested that the equatorial westward propagation of SST annual cycle is primarily due to the zonal heat advection. Therefore, the mechanism responsible for the westward propagation of equatorial SST in this model is the feedback between the zonal wind and SST through zonal advection. Here, the zonal advection is not only directly driven by the zonal wind, but also enhanced by the associated Rossby waves which move westward with the zonal wind and SST. If we intentionally exclude the Rossby waves in the coupled model by fixing the mixed layer depth and thermocline depth on the annual mean, the westward propagation of SST and zonal wind still exists, but the speed is slightly slower.

\section{2) Semiannual cycle of SSt in the Western PACIFIC}

In the equatorial western Pacific (EWP; $4^{\circ} \mathrm{S}-2^{\circ} \mathrm{N}$, $\left.120^{\circ}-160^{\circ} \mathrm{E}\right)$, the observed seasonal variation of the surface wind speed shows an obvious semiannual cycle (Fig. 12a). It has been qualitatively captured by the cou- pled control run, though the amplitude is larger than the observations. Two maxima (minima) of surface wind speed occur in February and August (April-May and November). The westerly and northerly in boreal winter (Figs. 12b,c) as well as the easterly and southerly in boreal summer are responsible for the two maximum wind speeds. The transition periods of the wind reversal correspond to the two minimum wind speeds.

In boreal winter, the Australian summer monsoon acts to increase the westerly and northerly winds (Figs. $12 \mathrm{~b}, \mathrm{c})$. In boreal summer, the Asian summer monsoon intensifies the easterly and southerly winds. The resultant semiannual wind speeds cause semiannual variations in the latent heat flux that, along with the semiannual solar radiation, determine the SST semiannual cycle in the EWP.

Without the continental monsoons (PAC; Table 2), the annual variability of meridional wind is small (Fig. 12c). The observed easterly in boreal summer is almost missing (Fig. 12b). Thus, the resultant total wind speed is dominated by an annual cycle (Fig. 12a), which forces a fictitious SST annual cycle in this region (Fig. 8d) though the solar radiation is still dominated by a semiannual cycle. Mechoso et al. (1995) evaluated the performances of 11 coupled GCMs on simulating the equatorial Pacific annual cycle and concluded that most of the CGCMs are problematic in reproducing the SST annual cycle in the central-eastern equatorial Pacific. If one focuses on the seasonal marches of SST in the equatorial western Pacific, one would find that the CGCMs' performances are even worse. Only 1 or 2 out of the 11 CGCMs capture the semiannual cycle of SST in the EWP. A possible reason is the inappropriate simulation of the annual reversal of the surface winds in this region.

\section{3) Annual CyCle of SST In the EAStern PACIFIC}

The annual cycles of SST, zonal winds, and meridional winds in the EPCT $\left(4^{\circ} \mathrm{S}-2^{\circ} \mathrm{N}, 120^{\circ}-90^{\circ} \mathrm{W}\right)$ from the five experiments with the coupled model (CTL, PAC, ASM, NAM, and SAM; Table 2) are presented in Fig. 13 accompanying the observations. The results from all five experiments can be roughly divided into two groups. One is the PAC, ASM, and NAM; the other is the CTL and SAM. The simulated amplitudes of SST annual cycles for the first group are $50 \%$ or less than those of the observations and the control run. Their phases lag the observations and the control run by $2-$ 3 months in the cold season. The corresponding annual cycles of meridional winds (Fig. 13c) show a similar annual phase to the control run, but the amplitudes are half. The annual cycles of the simulated zonal winds for the PAC, ASM, and NAM experiments differ considerably from those of the observations and the control run. The westerly perturbations in early spring are very small. The easterly perturbations in early summer are 
(a) Diffrence of Annual Mean SST (CTL-PAC)

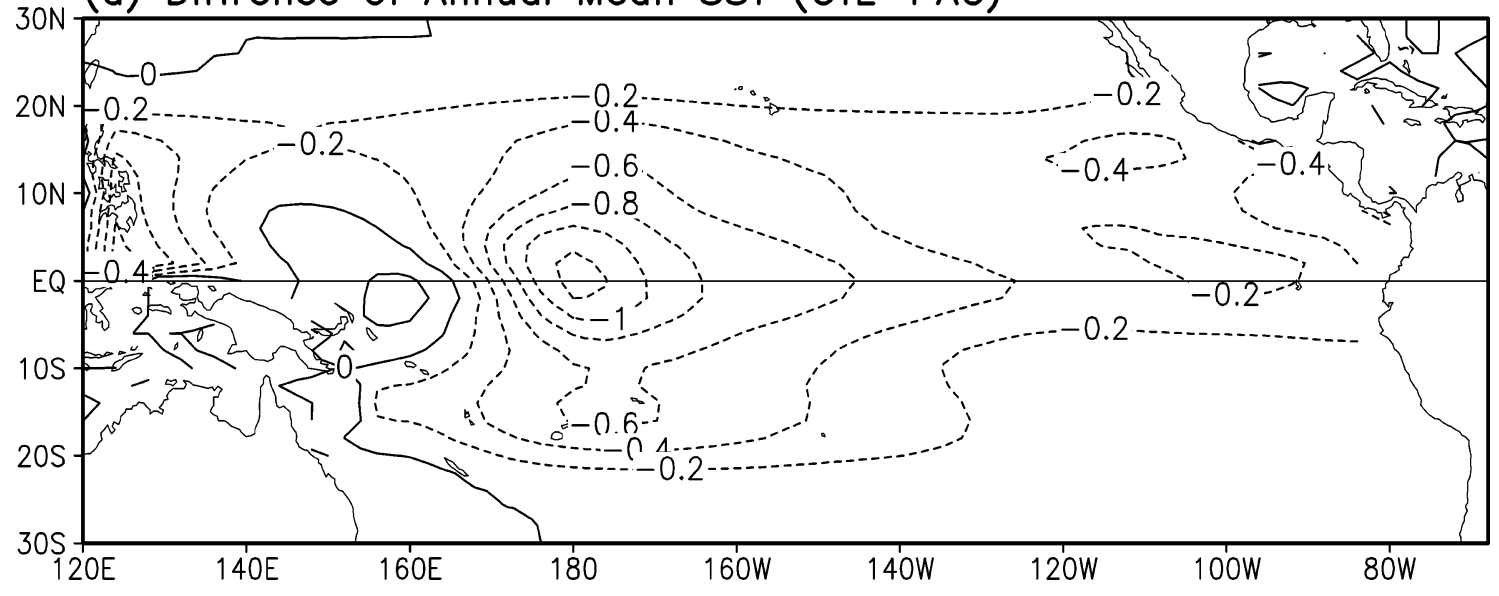

(b) Differences of Surface Winds (CTL-PAC)

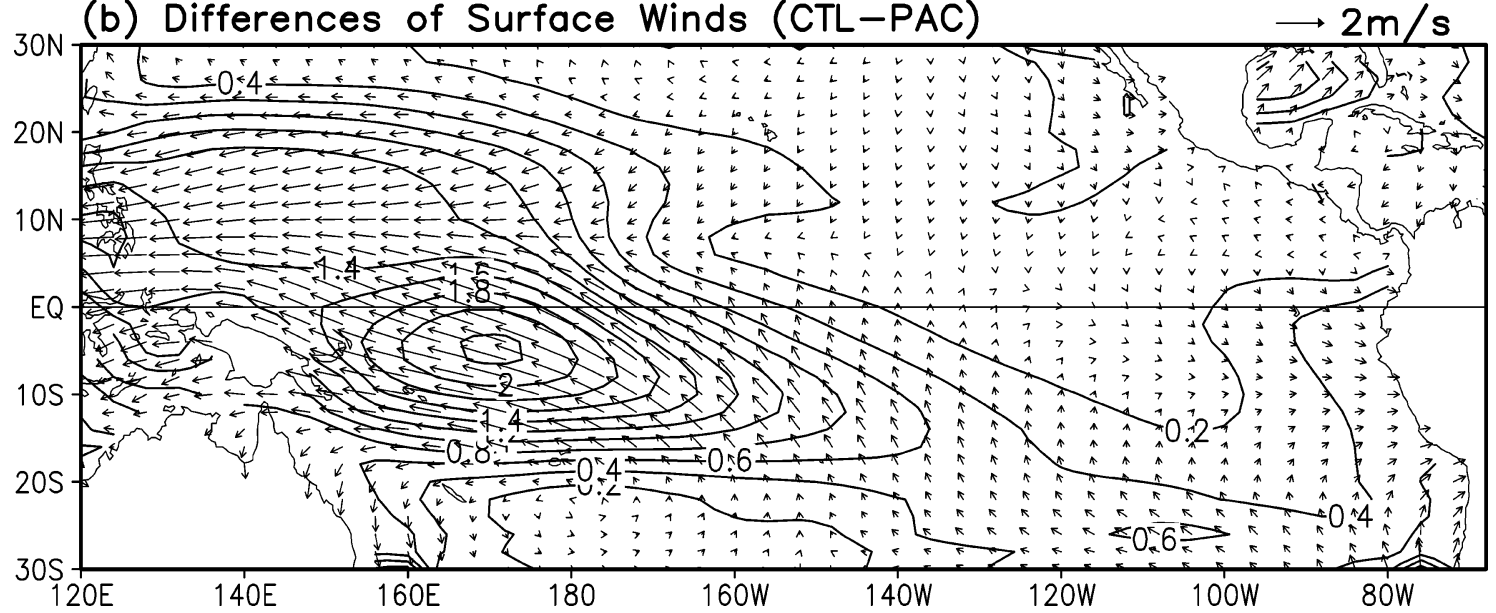

FIG. 10. The differences of the annual mean (a) SST (contour interval of $0.2^{\circ} \mathrm{C}$ ) and (b) surface winds (the contours show the wind speed with $0.2 \mathrm{~m} \mathrm{~s}^{-1}$ interval) between the coupled control run (CTL; Table 2) and the run without adjacent continental monsoons (PAC; Table 2).

almost missing in all the three experiments. After inclusion of the impacts from the SAM, the resulting annual cycles of SST, zonal, and meridional winds are very similar to those of the control run. This confirms that the South American monsoon exerts substantial impact on the SST annual cycle in the eastern Pacific by changing the surface winds.

From March to May, the cooling associated with the northward retreat of the South American summer monsoon apparently strengthens the southeasterly trades in the eastern tropical Pacific (Fig. 7c). These southeasterly winds are primarily driven by the increased northwest pressure gradient associated with the diabatic cooling in the South American continent (Nigam 1997). The increase of the southeasterly trades intensifies the surface evaporation, the oceanic entrainment, and cold advection. These combined effects contribute to the rapid reestablishment of the equatorial Pacific cold tongue.

The agreement of SST annual cycles between the
NAM and the PAC suggests that the North American continental monsoons do not play an appreciable role in the annual cycle of SST in the equatorial Pacific. Actually, this should be expected if we consider the small portion of the rainfall contributed by the North American continental monsoons to the total North American monsoon rainfall (Fig. 1c; Horel et al. 1989). This result does not seem to support the hypothesis of Mitchell and Wallace (1992) about the role of Colombian and Central American monsoons on the reestablishment of the eastern Pacific cold tongue.

\section{c. Coupling between the ITCZ and the cold tongue}

The cold tongue reaches the weakest phase in March and April. From March to May, pronounced northward low-level flows develop over the eastern Pacific. Mitchell and Wallace (1992) suggested that the intensifying northward wind stress brings colder water to the surface 
(a) Diff. of EQ SST Annual Cycle (NAM-ASM)

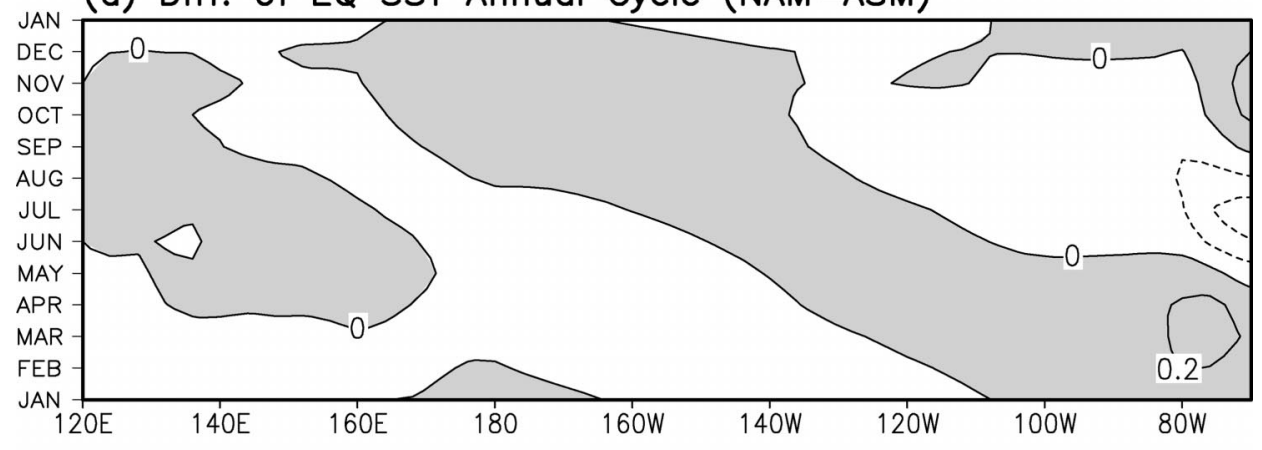

(b) Diff. of EQ $\cup$ Annual Cycle (NAM-ASM)

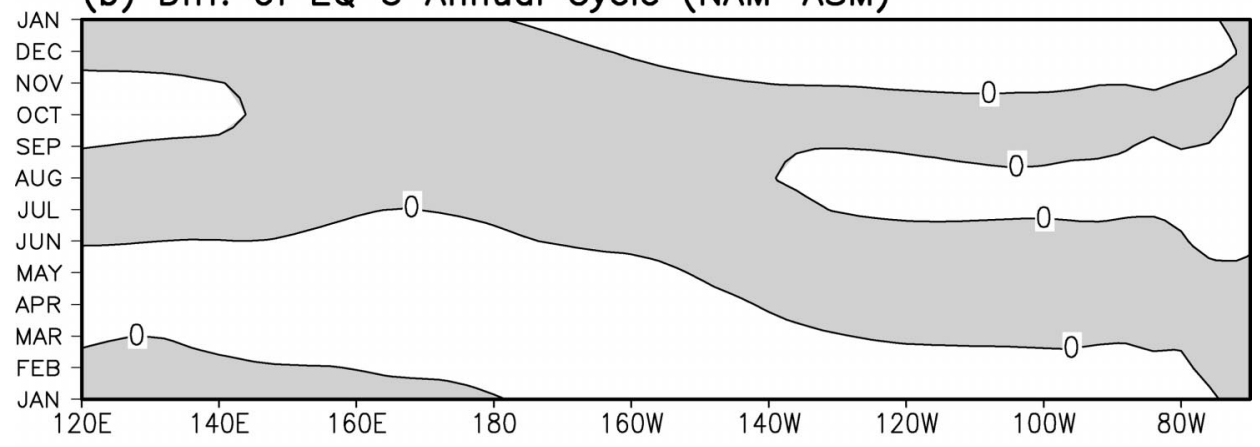

(c) Diff. of EQ SST Annual Cycle (SAM-NAM)

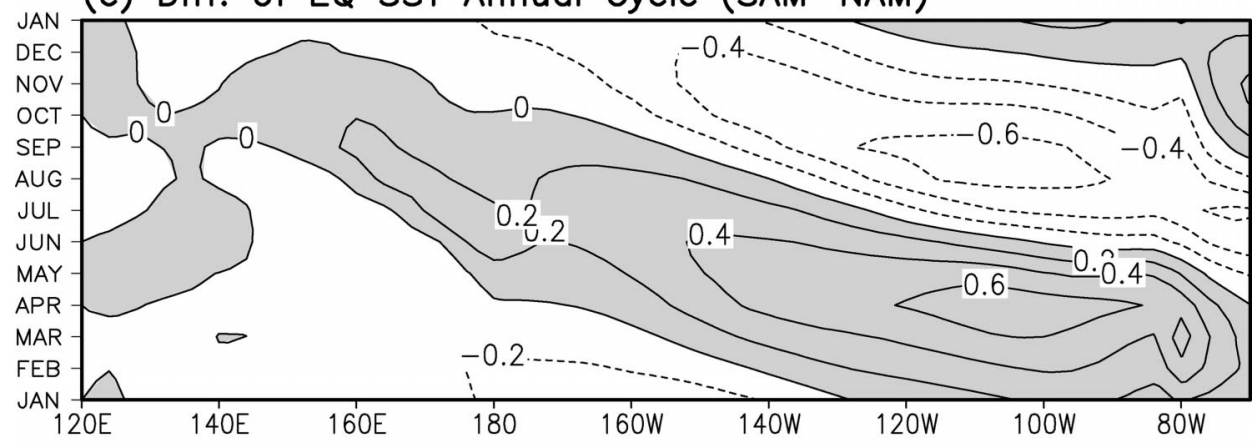

(d) Diff. of EQ $\cup$ Annual Cycle (SAM-NAM)

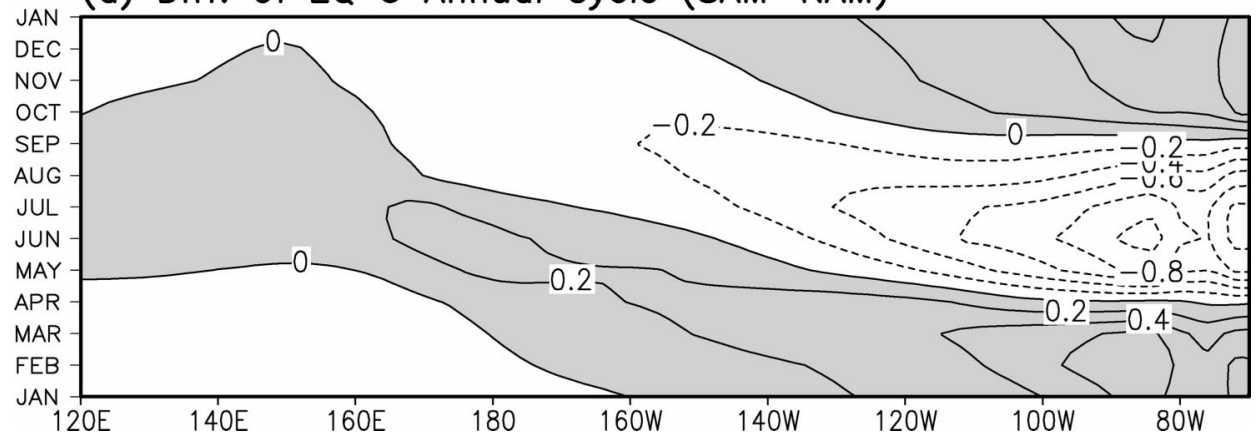

FIG. 11. The equatorial annual perturbations of (a) SST, (b) zonal winds caused by the North American continental monsoons (NAM - ASM; Table 2); (c) SST and (d) zonal winds caused by the South American

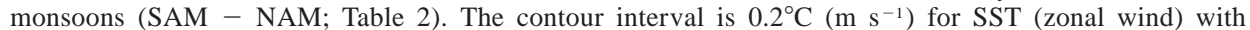
positive SST and westerly wind shaded. 
(a) Total Wind Speed $(\mathrm{m} / \mathrm{s}, 120 \mathrm{E}-160 \mathrm{E}, 4 \mathrm{~S}-2 \mathrm{~N})$

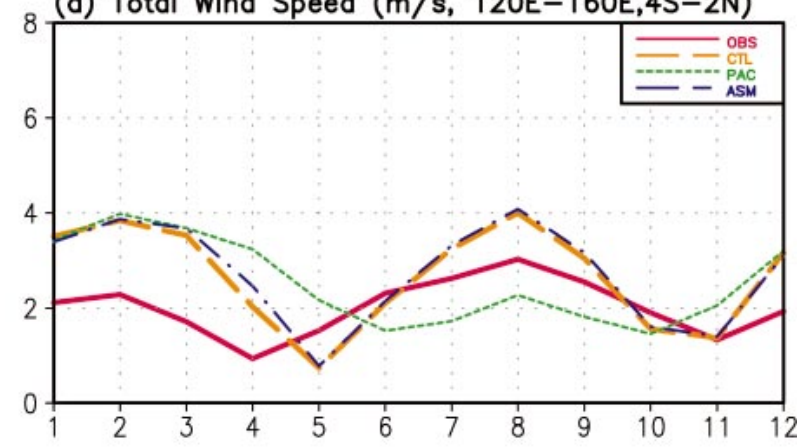

(b) Zonal Wind Component (m/s)

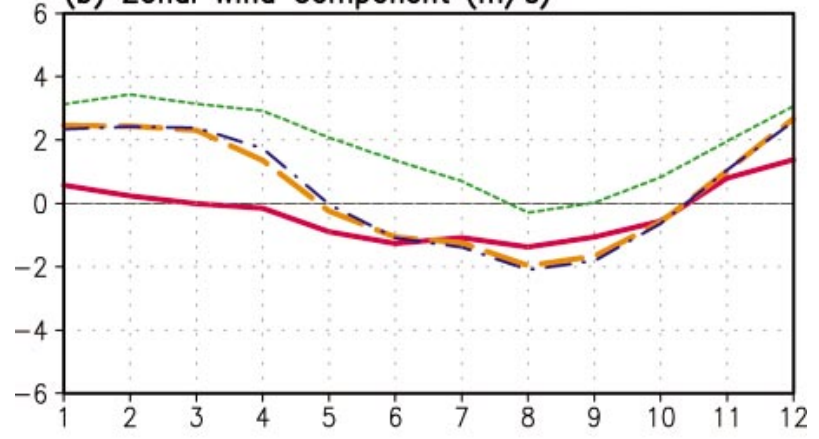

(c) Meridional Wind Component $(\mathrm{m} / \mathrm{s})$

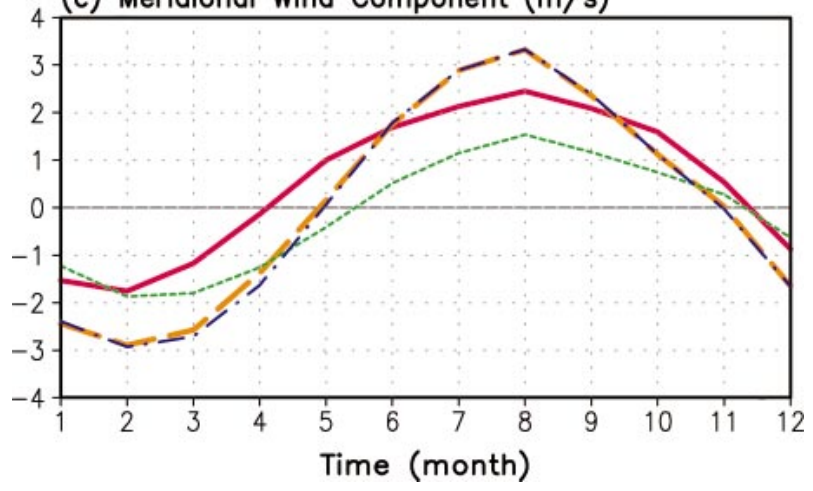

FIG. 12. The annual variations of (a) surface wind speed $\left(\mathrm{m} \mathrm{s}^{-1}\right)$, (b) zonal wind component, and (c) meridional wind component in the equatorial western Pacific $\left(4^{\circ} \mathrm{S}-2^{\circ} \mathrm{N}, 120^{\circ}-160^{\circ} \mathrm{E}\right)$ from the observations (OBS), the coupled control run (CTL; Table 2), the run without adjacent continental monsoons (PAC; Table 2) and the run with the Asian-Australian monsoons (ASM; Table 2).

near the equator, to reestablish the cold tongue. Cooling in the atmospheric planetary boundary layer above the cold tongue would cause sea level pressure to rise locally, increasing the northward flow and the equatorial upwelling. The enhanced northward flow also intensifies the convection over the ITCZ, which will further intensify the northward flow. Based on the above arguments, Mitchell and Wallace (1992) suggested that the annual marches of the ITCZ/cold tongue complex are self-sustained.

In this section, with the above coupled numerical experiments, we try to see to what degree the annual marches of the ITCZ/cold tongue complex are self-sustained. Figure 14a shows the annual variations of rainfall in the eastern ITCZ from all the five experiments (CTL, PAC, ASM, NAM, and SAM; Table 2) and the observations. The observed rainfall is smallest in FebruaryMarch, then rapidly increases to the maximum in JuneJuly. The annual variations of the rainfall are reasonably reproduced in all the five coupled experiments except that the magnitude from May to December is smaller than the observations by $2 \mathrm{~mm}$ day $^{-1}$. In contrast to the SST annual cycles in the EPCT (Fig. 13a), all five experiments produce very similar SST annual cycles under the ITCZ, particularly in the warm phase (Fig. 14b). These results imply that the intensification of the rainfall in the eastern ITCZ from March to May is probably due to the warming of the water under the ITCZ rather than the cooling of the cold tongue as shown in section $3 \mathrm{c}$ (Fig. 6).

Though the ITCZ rainfall in the three experiments (PAC, ASM, and NAM) is nearly the same as in the CTL, the SST annual cycles over the EPCT are quite different from that in the CTL (Fig. 13a). In other words, the intensification of the ITCZ rainfall from March to May does not necessarily sustain the corresponding cooling of cold tongue as in the control run. Why does the self-sustained hypothesis of the ITCZ/cold tongue complex not work in this coupled model? Referring to Fig. 6c, we find that the stationary diabatic heating associated with the onset of the ENPSM forces not only a southerly wind perturbation in the eastern equatorial Pacific but also a westerly wind component along the equator to the west of $100^{\circ} \mathrm{W}$. This is consistent with the results of Nigam (1997, see his Fig. 10c). The southerly wind definitely cools the sea surface in the cold tongue. A positive coupling between the ITCZ and the cold tongue is established as suggested by Mitchell and Wallace (1992). However, the equatorial westerly wind favors the warming of the cold tongue. This process is against the positive meridional coupling between the ITCZ and the cold tongue and is overlooked in the selfsustained hypothesis.

From Fig. 13a, we see that without the remote forces from the South American continent, the amplitude of the SST annual cycle in the EPCT is only about half of the control run and the observations. This suggests that the air-sea coupling in the tropical Pacific alone accounts for only half of the annual variability of the SST in the cold tongue. The other half is caused by the South American continental monsoon.

\section{Summary and discussion}

An intermediate atmosphere-ocean coupled model and its atmospheric component in the global Tropics $\left(30^{\circ} \mathrm{S}-30^{\circ} \mathrm{N}\right)$ have been used to study the roles of adjacent continental monsoons and air-sea coupling on the mean state and annual cycle of the equatorial Pacific. Both adjacent continental monsoons and air-sea cou- 
(a) SST Annual Cycle (C, 120W-90W,4S-2N)

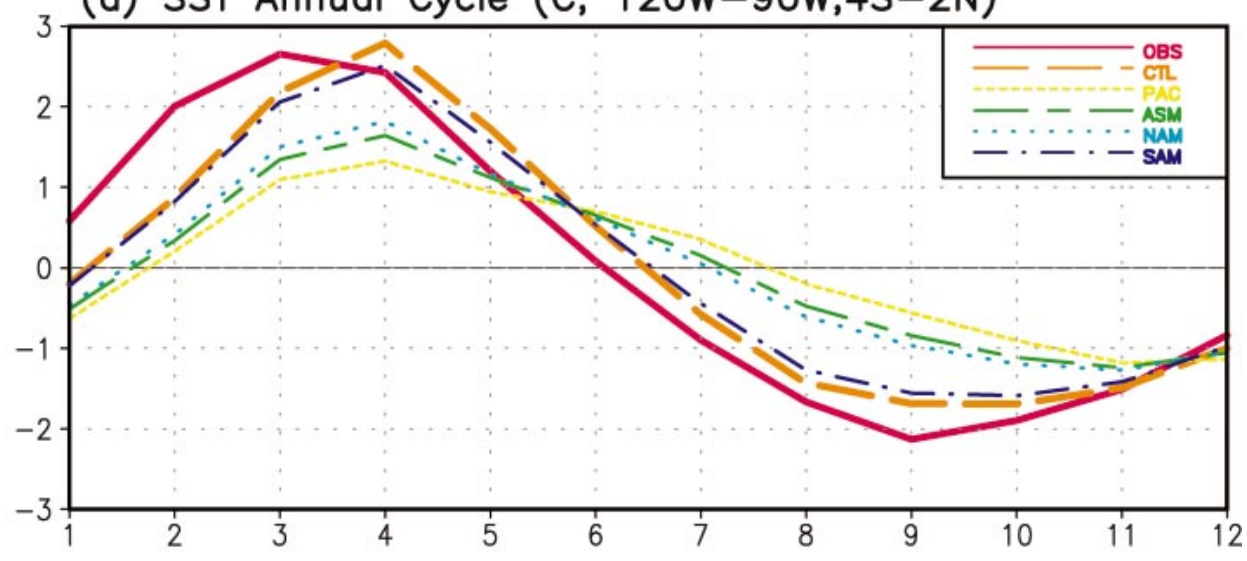

(b) Zonal Wind Annual Cycle ( $\mathrm{m} / \mathrm{s}$ )

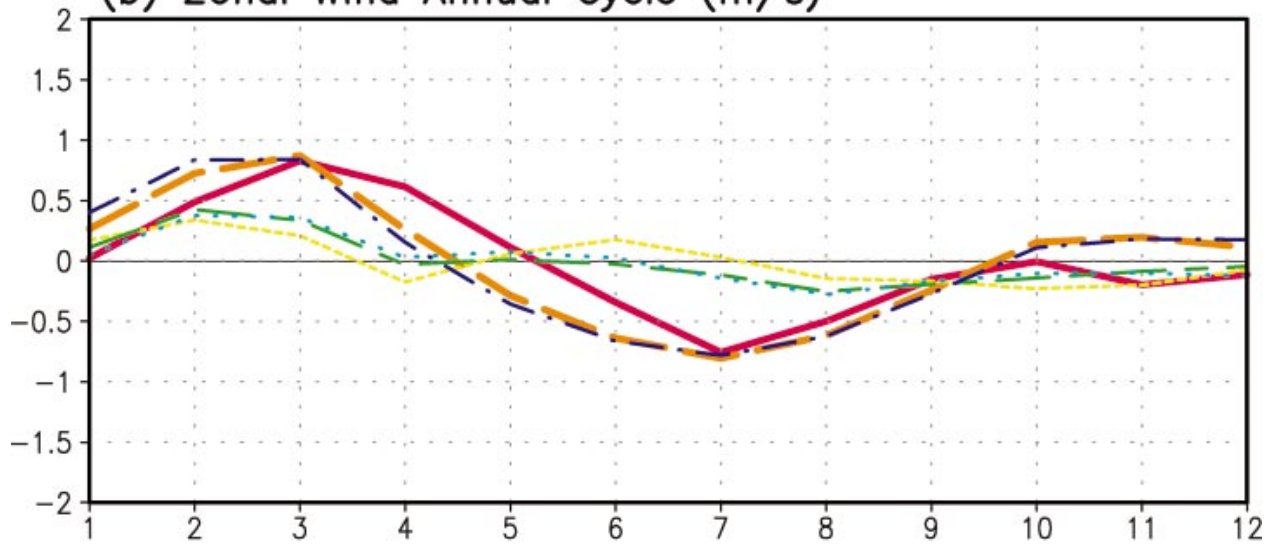

(c) Meridional Wind Annual Cycle $(\mathrm{m} / \mathrm{s})$

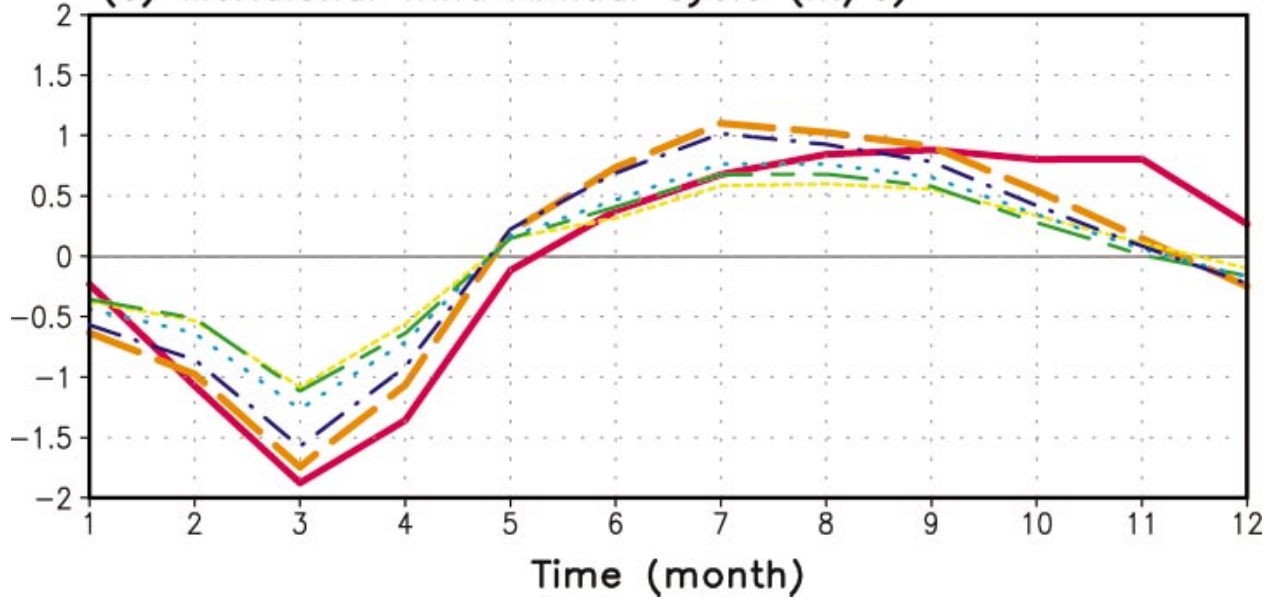

FIG. 13. The annual cycles of (a) SST, (b) zonal wind, and (c) meridional wind in the EPCT $\left(4^{\circ} \mathrm{S}-2^{\circ} \mathrm{N}\right.$, $120^{\circ}-90^{\circ} \mathrm{W}$ ) from the observations (OBS), the coupled control run (CTL; Table 2), the run without adjacent continental monsoons (PAC; Table 2), the run with the Asian-Australian monsoon (ASM; Table 2), the run with the North American continental monsoon (NAM; Table 2), and the run with the South American monsoon (SAM; Table 2).

pling are found to be important for a realistic simulation of the climate of the equatorial Pacific.

Without the impacts from the adjacent continental monsoons, Pacific-only air-sea coupling is able to es- tablish the equatorial warm pool/cold tongue structure and the ITCZ/cold tongue complex in the eastern $\mathrm{Pa}$ cific. However, the simulated warm pool shifts to the central Pacific and the trades in the western-central Pa- 
(a) Rainfall Annual Cylce in ITCZ ( $\mathrm{mm} /$ day)

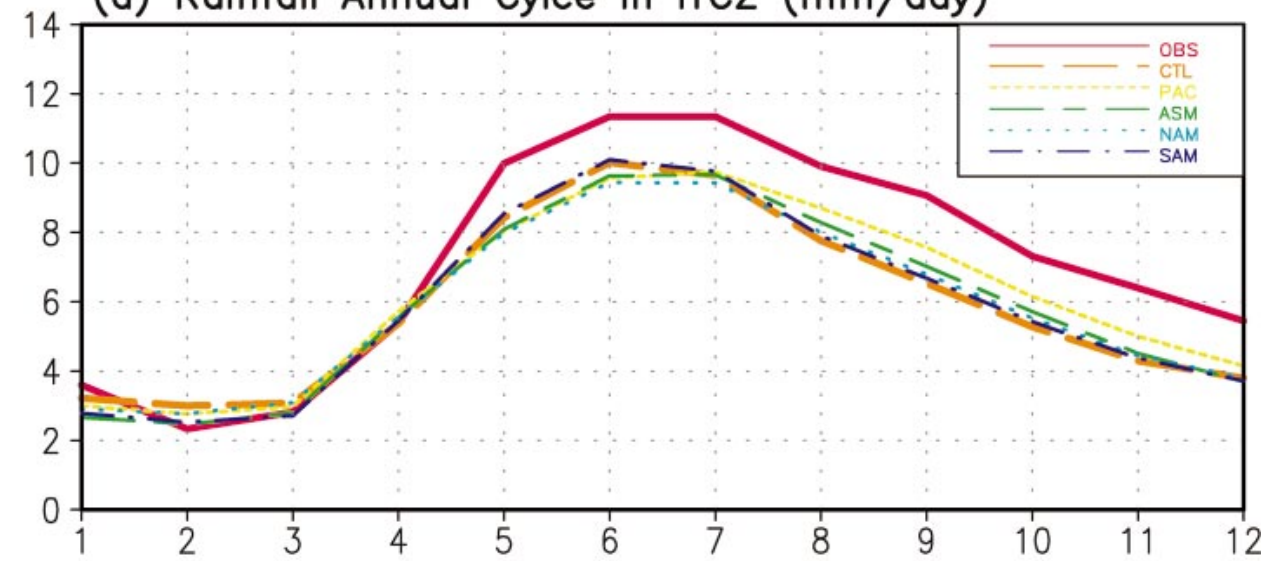

(b) SST Annual Cycle in ITCZ(C)

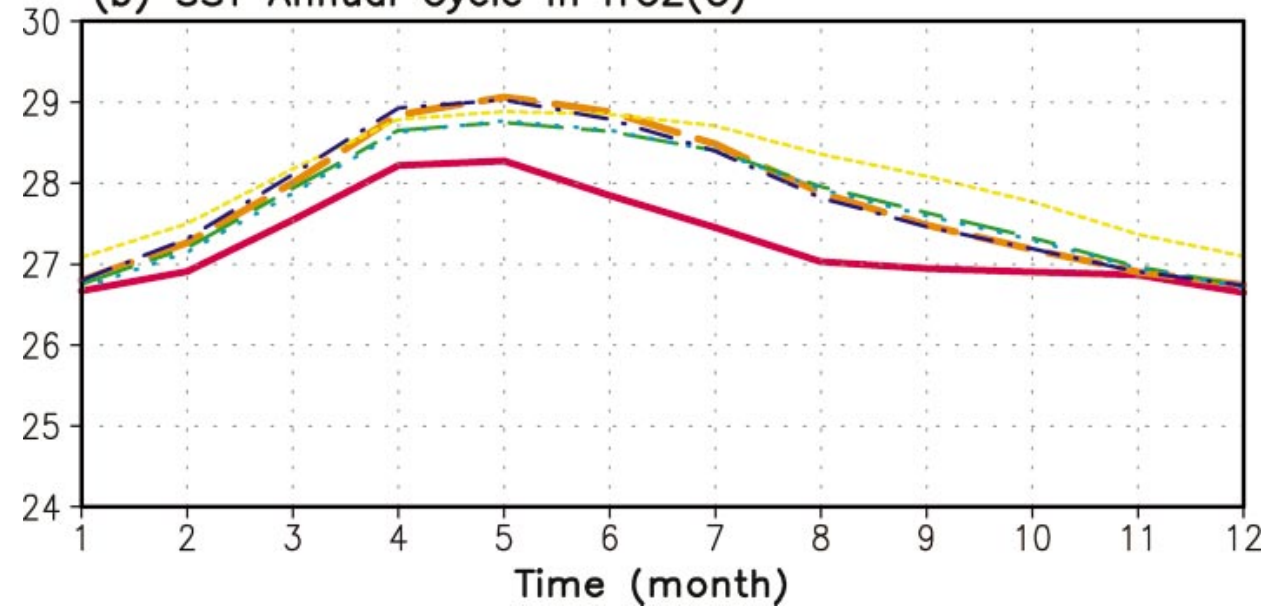

FIG. 14. The annual variations of (a) rainfall, (b) SST in the eastern ITCZ $\left(4^{\circ}-10^{\circ} \mathrm{N}, 120^{\circ}-90^{\circ} \mathrm{W}\right)$ from the observations (OBS), the coupled control run (CTL; Table 2), the run without adjacent continental monsoons (PAC; Table 2), the run with the Asian-Australian monsoon (ASM; Table 2), the run with the North American continental monsoon (NAM; Table 2), and the run with the South American monsoon (SAM; Table 2).

cific are too weak. It also produced a fairly weak annual cycle in the eastern Pacific and a fictitious annual cycle in the western Pacific (Fig. 8d). The annual marches of the ITCZ/cold tongue complex are not fully sustained by the air-sea coupling alone. The onset of the rainy season in the ITCZ (from March to May) is primarily due to the warming of the water under the ITCZ. The diabatic heating associated with the ITCZ rainfall enhances both the southerly and westerly winds near the equator. The former causes the decrease of SST in the cold tongue. A positive coupling is established between the ITCZ and the cold tongue as suggested by Mitchell and Wallace (1992). However, the equatorial westerly perturbation associated with the enhanced ITCZ rainfall favors the warming of the cold tongue. This negative feedback weakens the meridional positive coupling. Further, the adjacent continental monsoons will not produce a westward-propagating zonal wind along the equatorial Pacific. It is the air-sea coupling that is responsible for the equatorial westward propagation of the annual cycle of SST. The dominant feedbacks are among the zonal wind, zonal heat advection, and the SST gradient.

The Asian-Australian monsoons can rectify the mean of the equatorial Pacific SST and thermocline slope by changing the mean strength of trades in the westerncentral Pacific (Fig. 10). The reason is that, associated with the Asian-Australian monsoons, rainfall within the equatorial waveguide in the Indian sector is larger than that without any annual varying forces. The convective heating due to this increased rainfall forces a Kelvin wave response (Gill 1980), thus enhancing the easterly wind and cooling the water over the western-central Pacific, thus resulting in better simulations of surface winds and SST in the equatorial western Pacific (Fig. 9). The Asian-Australian monsoons also generate a semiannual cycle of surface wind speed in the western Pacific, which is significant for the formation of SST semiannual cycle there.

The American continental monsoons primarily affect 
the annual cycles of the eastern Pacific, but not the annual mean. The Colombian and Central American continental monsoons have little influence on the annual cycle of SST in the cold tongue (Fig. 11a). However, the South American monsoon exerts profound impacts on the annual variations of the southeast trades in the eastern Pacific. It is found to be the most important external forcing on the SST annual cycle of the equatorial eastern Pacific (Figs. 11c,d). During the reestablishment phase of the cold tongue (from March to May), the diabatic cooling over the South American continent associated with the northward retreat of the South American summer monsoon intensifies the southeast trades in the eastern Pacific (Nigam 1997). The intensified trades help cool the cold tongue by enhancing the latent heat flux, oceanic entrainment, and cold advection. Our result suggests that the Pacific-only, air-sea coupling accounts for half of the annual variability of the SST in the eastern Pacific cold tongue. The remote forcing from South America accounts for the other half (Fig. 13a).

Through this study, we found the important roles of Asian-Australian monsoons on rectifying the mean state of the western Pacific and South American monsoon on the annual cycle of the eastern Pacific, pointing to these two monsoons as possible regulators of the equatorial Pacific climate. However, due to the simplicity of the models used, our results certainly bear some uncertainties in the quantitative sense. The major uncertainties probably come from the following three aspects: the specified clouds, weak transient activities, and simple orographic effects. The clouds in the coupled system primarily influence the atmospheric heating gradient and surface solar radiation. Therefore, with the specified clouds, part of the surface wind fields and SST fields are built into the models. One possible implication is that the impacts from the adjacent continent monsoons on the equatorial Pacific SST climate may be underestimated in this study. Synoptic transient processes are active in the ITCZ and the eastern North Pacific summer monsoon. These processes may be important to connect the Central American continental monsoon with the convection in the eastern ITCZ (or the ENPSM). Underestimated transient activities in the intermediate atmospheric model may weaken the connection between the Central-North American continental monsoons with the eastern Pacific ITCZ, and thus the equatorial cold tongue. The topography in the west coast of the American continent may play an important role in shaping the flows over the eastern tropical Pacific. The orographic effects in the intermediate model are parameterized simply with a viscous mountain by increasing surface friction. To clear up these uncertainties, further studies with high-resolution regional and global models are needed. The studies with atmospheric GCMs and hybrid-coupled models are under way.
Acknowledgments. This work was supported by the National Oceanic and Atmospheric Administration (NOAA) Pan-American Climate Study (PACS) program. Comments from two anonymous reviewers helped improve the manuscript. The authors thank Diane Henderson for editing the manuscript. The International Pacific Research Center is partly sponsored by the Frontier Research System for Global Change.

\section{REFERENCES}

Chang, P., 1996: The role of the dynamic ocean-atmosphere interactions in the tropical seasonal cycle. J. Climate, 9, 2973-2998. , and S. G. Philander, 1994: A coupled ocean-atmosphere instability of relevance to seasonal cycle. J. Atmos. Sci., 51, 36273648.

Fu, X., 1998: Simulation of the tropical Pacific annual cycle with an intermediate atmosphere-ocean-land model. Ph.D. thesis, University of Hawaii at Manoa, $229 \mathrm{pp}$.

- and B. Wang, 1999: On the role of the longwave radiation and boundary layer thermodynamics in forcing tropical surface winds. J. Climate, 12, 1049-1069.

— cycle of the Pacific cold tongue. Part I: Simulation and sensitivity experiments. J. Climate, 14, 765-779.

Garrat, J. R., 1977: Review of drag coefficients over oceans and continents. Mon. Wea. Rev., 105, 915-929.

Gaspar, P., 1988: Modeling the seasonal cycle of the upper ocean. $J$. Phys. Oceanogr., 18, 161-180.

Gill, A. E., 1980: Some simple solutions for heat-induced tropical circulation. Quart. J. Roy. Meteor. Soc., 106, 447-462.

Horel, J. D., 1982: On the annual cycle of the tropical Pacific atmosphere and ocean. Mon. Wea. Rev., 110, 1863-1878.

__ A. N. Hahmann, and J. E. Geisler, 1989: An investigation of the annual cycle of convective activity over the Tropical Americas. J. Climate, 2, 1388-1403.

Inness, P. M., J. M. Slingo, E. Guilyardi, and J. Cole, 2003: Simulation of the Madden-Julian Oscillation in a coupled general circulation model. Part II: The role of the basic state. J. Climate, 16, 365382 .

Jin, F. F., 1998: A simple model for the Pacific cold tongue and ENSO. J. Atmos. Sci., 55, 2458-2469.

__ J. D. Neelin, and M. Ghil, 1994: El Niño on the devil's staircase: Annual subharmonic steps to chaos. Science, 264, 70-72.

Krishnamurti, T. N., 1985: Summer monsoon experiment-Review. Mon. Wea. Rev., 113, 1590-1626.

Li, T., and S. G. H. Philander, 1996: On the annual cycle of the eastern equatorial Pacific. J. Climate, 9, 2986-2997.

Liu, Z. Y., and S. P. Xie, 1994: Equatorial propagation of coupled air-sea disturbances with application to the annual cycle of the eastern tropical Pacific. J. Atmos. Sci., 51, 3807-3822.

Matsuno, T., 1966: Numerical integration of primitive equation by use of a simulated backward difference method. J. Meteor. Soc. Japan, 44, 76-84.

McCreary, J. P., and Z. J. Yu, 1992: Equatorial dynamics in a 2.5layer model. Progress in Oceanography, Vol. 29, Pergamon, 61132.

Mechoso, C. S., and Coauthors, 1995: The seasonal cycle over the tropical Pacific in coupled ocean-atmosphere general circulation models. Mon. Wea. Rev., 123, 2825-2838.

Miller, M. J., and A. J. Thorpe, 1981: Radiational conditions for the lateral boundaries of limited area numerical models. Quart. J. Roy. Meteor. Soc., 107, 615-628.

Mitchell, T. P., and J. M. Wallace, 1992: On the annual cycle in equatorial convection and sea surface temperature. J. Climate, 5, 1140-1156.

Murakami, T., and B. Wang, 1993: Annual cycle of equatorial east- 
west circulation over the Indian and Pacific Oceans. J. Climate, 6, 932-952.

_ _ _ _ and S. W. Lyons, 1992: Summer monsoons over the Bay of Bengal and the eastern North Pacific. J. Meteor. Soc. Japan, 70, 191-210.

Neelin, J. D., and H. A. Dijkstra, 1995: Ocean-atmosphere interaction and the tropical climatology. Part I: The dangers of flux correction. J. Climate, 8, 1325-1342.

Nigam, S., 1997: The annual warm to cold phase transition in the eastern equatorial Pacific: Diagnosis of the role of stratus cloudtop cooling. J. Climate, 10, 2447-2467.

Philander, S. G. H., 1990: El Niño, La Niña and the Southern Oscillation. Academic Press, 293 pp.

— D. D. Gu, D. Halpern, G. Lambert, N.-C. Lau, T. Li, and R. C. Pacanowski, 1996: Why the ITCZ is mostly north of the equator. J. Climate, 9, 2958-2972.

Reynolds, R. W., 1988: A real-time global sea surface temperature analysis. J. Climate, 1, 75-86.

Robertson, A. W., C. C. Ma, C. R. Mechoso, and M. Ghil, 1995: Simulation of tropical Pacific climate with a coupled oceanatmosphere general circulation model. Part I: The seasonal cycle. J. Climate, 8, 1178-1198.

Rossow, W. B., L. C. Garder, P. J. Lu, and A. Walker, 1988: International Satellite Cloud Climatology Project (ISCCP) Documentation of Cloud Data. WMO/TD-No. 266, World Climate Research Program (ICSU/WMO), 75 pp.

Schneider, E. K., 2002: Understanding differences between the equatorial Pacific as simulated by two coupled GCMs. J. Climate, 15, 449-469.

_, Z. Zhu, B. S. Giese, B. Huang, B. D. Kirtman, J. Shukla, and J. A. Carton, 1997: Annual cycle and ENSO in a coupled oceanatmosphere general circulation model. Mon. Wea. Rev., 125, 680-702.

Slingo, A., and J. M. Slingo, 1988: The response of a general circulation model to cloud longwave radiative forcing. Part I: Introduction and initial experiments. Quart. J. Roy. Meteor. Soc., 114, 1027-1062.
Stone, P. H., and R. M. Chervin, 1984: Influence of ocean surface temperature gradient and continentality on Walker circulation. Part II: Prescribed global changes. Mon. Wea. Rev., 112, 15241534.

Wang, B., 1994: On the annual cycle in the tropical eastern central Pacific. J. Climate, 7, 1926-1942.

_- and T. Li, 1993: A simple tropical model of relevance to shortterm climate variations. J. Atmos. Sci., 50, 260-284.

- , and Y. Wang, 1999: Dynamics of the ITCZ-equatorial cold tongue complex and causes of the latitudinal climate asymmetry. J. Climate, 12, 1830-1847.

_- and X. Fu, 2001: Physical processes determining the rapid reestablishment of the equatorial cold tongue/ITCZ complex. $J$. Climate, 14, 2250-2264.

—_ and S. I. An, 2002: A mechanism for decadal changes of ENSO behavior: Roles of background wind changes. Climate Dyn., 18, 475-486.

_, T. Li, and P. Chang, 1995: An intermediate model of the tropical Pacific Ocean. J. Phys. Oceanogr., 25, 1599-1616.

Xie, P. P., and P. A. Arkin, 1996: Analyses of global monthly precipitation using gauge observations, satellite estimates, and numerical model predictions. J. Climate, 9, 840-858.

Xie, S. P., 1994: On the genesis of the equatorial annual cycle. $J$. Climate, 7, 2008-2013.

__ 1998: Ocean-atmosphere interaction in the making of the Walker circulation and the equatorial cold tongue. J. Climate, 11, 189-201.

__ , and K. Saito, 2001: Formation and variability of a northerly ITCZ in a hybrid coupled AGCM: Continental forcing and oceanic-atmospheric feedback. J. Climate, 14, 1262-1276.

Yu, J. Y., and C. R. Mechoso, 1999: Links between annual variations of Peruvian stratocumulus clouds and of SST in the east equatorial Pacific. J. Climate, 12, 3305-3318.

Zebiak, S. E., and M. A. Cane, 1987: A model El Niño and Southern Oscillation. Mon. Wea. Rev., 115, 2262-2278.

Zhou, J. Y., and K.-M. Lau, 1998: Does a monsoon climate exist over South America? J. Climate, 11, 1020-1040. 